University of Nebraska - Lincoln

DigitalCommons@University of Nebraska - Lincoln

\title{
Energy Balance Closure at FLUXNET Sites
}

\author{
Kell Wilson \\ Atmospheric Turbulence and Diffusion Division, NOAA, P.O. Box 2456, Oak Ridge, TN \\ Allen Goldstein \\ ESPM, University of California at Berkeley, Berkeley, CA 94720, USA \\ Eva Falge \\ Pflanzenökologie, University Bayreuth, 95440 Bayreuth, Germany \\ Marc Aubinet \\ Unité de Physique, Faculté des Sciences Agronomiques de Gembloux, B-50 30 Gembloux, Belgium \\ Dennis D. Baldocchi \\ University of California - Berkeley, baldocchi@berkeley.edu \\ See next page for additional authors
}

Follow this and additional works at: https://digitalcommons.unl.edu/natrespapers

Part of the Natural Resources and Conservation Commons

\begin{abstract}
Wilson, Kell; Goldstein, Allen; Falge, Eva; Aubinet, Marc; Baldocchi, Dennis D.; Berbigier, Paul; Bernhofer, Christian; Ceulemans, Reinhart; Dolman, Han; Field, Chris; Grelle, Achim; Ibrom, Andreas; Law, B. E.; Kowalski, Andy; Meyers, Tilden; Moncrieff, John; Monson, Russ; Oechel, Walter; Tenhunen, John; Verma, Shashi; and Valentini, Riccardo, "Energy Balance Closure at FLUXNET Sites" (2002). Papers in Natural Resources. 153.

https://digitalcommons.unl.edu/natrespapers/153
\end{abstract}

This Article is brought to you for free and open access by the Natural Resources, School of at DigitalCommons@University of Nebraska - Lincoln. It has been accepted for inclusion in Papers in Natural Resources by an authorized administrator of DigitalCommons@University of Nebraska - Lincoln. 


\section{Authors}

Kell Wilson, Allen Goldstein, Eva Falge, Marc Aubinet, Dennis D. Baldocchi, Paul Berbigier, Christian Bernhofer, Reinhart Ceulemans, Han Dolman, Chris Field, Achim Grelle, Andreas Ibrom, B. E. Law, Andy Kowalski, Tilden Meyers, John Moncrieff, Russ Monson, Walter Oechel, John Tenhunen, Shashi Verma, and Riccardo Valentini 


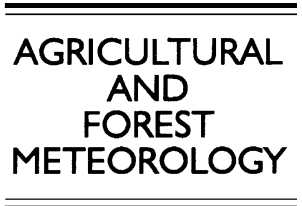

Agricultural and Forest Meteorology 113 (2002) 223-243

www.elsevier.com/locate/agrformet

\title{
Energy balance closure at FLUXNET sites
}

\author{
Kell Wilson ${ }^{\mathrm{a}}$, Allen Goldstein ${ }^{\mathrm{b}}$, Eva Falge ${ }^{\mathrm{c}}$, Marc Aubinet ${ }^{\mathrm{d}}$, Dennis Baldocchi ${ }^{\mathrm{b}, *}$, \\ Paul Berbigier ${ }^{\mathrm{e}}$, Christian Bernhofer ${ }^{\mathrm{f}}$, Reinhart Ceulemans ${ }^{\mathrm{g}}$, Han Dolman ${ }^{\mathrm{h}}$, \\ Chris Field $^{i}$, Achim Grelle ${ }^{j}$, Andreas Ibrom ${ }^{k}$, B.E. Law ${ }^{1}$, Andy Kowalski ${ }^{g}$, \\ Tilden Meyers ${ }^{\mathrm{a}}$, John Moncrieff ${ }^{\mathrm{m}}$, Russ Monson ${ }^{\mathrm{n}}$, Walter Oechel ${ }^{\mathrm{o}}$, John Tenhunen ${ }^{\mathrm{c}}$, \\ Riccardo Valentini ${ }^{\mathrm{p}}$, Shashi Verma ${ }^{\mathrm{q}}$ \\ a Atmospheric Turbulence and Diffusion Division, NOAA, P.O. Box 2456, Oak Ridge, TN 37831, USA \\ ${ }^{\mathrm{b}}$ ESPM, University of California at Berkeley, Berkeley, CA 94720, USA \\ ${ }^{\mathrm{c}}$ Pflanzenökologie, University Bayreuth, 95440 Bayreuth, Germany \\ ${ }^{\mathrm{d}}$ Unité de Physique, Faculté des Sciences Agronomiques de Gembloux, B-50 30 Gembloux, Belgium \\ e Unité de Bioclimatologie, INRA Bourdeaux, Gazinet, France \\ f Insitute für Hydrologie und Meteorologie, 01737 Tharandt, Germany \\ ${ }^{g}$ Free University, Amsterdam, The Netherlands \\ h INRA Ecophysiology, Pierroton, France \\ ${ }^{\mathrm{i}}$ Department of Plant Biology, Carnegie Institution of Washington, Stanford, CA 94305, USA \\ ${ }^{\mathrm{j}}$ Department of Ecology and Environmental Research, Swedish University of Agricultural Sciences, S-750 07 Uppsala, Sweden \\ ${ }^{\mathrm{k}}$ Institut für Bioklimatologie, Georg-August University, Göttinen, Germany \\ ${ }^{1}$ College of Forestry, Oregon State University, Corvallis, OR 97331, USA \\ ${ }^{\mathrm{m}}$ Department of Ecology and Environmental Research, University of Edinburgh, Edinburgh, UK \\ ${ }^{\mathrm{n}}$ DEPOB, University of Colorado, Boulder, CO 80309, USA \\ ${ }^{\circ}$ Global Change Research Group, San Diego State University, San Diego, CA 92182, USA \\ ${ }^{\mathrm{p}}$ Department of Forest Science and Resources, University of Tuscia, 1-01100 Viterbo, Italy \\ ${ }^{q}$ School of Natural Resource Sciences, University of Nebraska, Lincoln, NE 68583, USA
}

Accepted 3 April 2002

\begin{abstract}
A comprehensive evaluation of energy balance closure is performed across 22 sites and 50 site-years in FLUXNET, a network of eddy covariance sites measuring long-term carbon and energy fluxes in contrasting ecosystems and climates. Energy balance closure was evaluated by statistical regression of turbulent energy fluxes (sensible and latent heat (LE)) against available energy (net radiation, less the energy stored) and by solving for the energy balance ratio, the ratio of turbulent energy fluxes to available energy. These methods indicate a general lack of closure at most sites, with a mean imbalance in the order of $20 \%$. The imbalance was prevalent in all measured vegetation types and in climates ranging from Mediterranean to temperate and arctic. There were no clear differences between sites using open and closed path infrared gas analyzers. At a majority of sites closure improved with turbulent intensity (friction velocity), but lack of total closure was still prevalent under most conditions. The imbalance was greatest during nocturnal periods. The results suggest that estimates of the scalar turbulent fluxes of sensible and LE are underestimated and/or that available energy is overestimated. The implications on interpreting long-term $\mathrm{CO}_{2}$ fluxes at FLUXNET sites depends on whether the imbalance results primarily from general errors associated
\end{abstract}

\footnotetext{
* Corresponding author. Tel.: +1-510-642-2874; fax: +1-510-643-5098
}

E-mail address: baldocchi@nature.berkeley.edu (D. Baldocchi). 
with the eddy covariance technique or from errors in calculating the available energy terms. Although it was not entirely possible to critically evaluate all the possible sources of the imbalance, circumstantial evidence suggested a link between the imbalance and $\mathrm{CO}_{2}$ fluxes. For a given value of photosynthetically active radiation, the magnitude of $\mathrm{CO}_{2}$ uptake was less when the energy imbalance was greater. Similarly, respiration (estimated by nocturnal $\mathrm{CO}_{2}$ release to the atmosphere) was significantly less when the energy imbalance was greater.

Published by Elsevier Science B.V.

Keywords: Energy balance; FLUXNET; Eddy covariance technique

\section{Introduction}

The global proliferation of long-term eddy covariance sites measuring carbon and energy fluxes (FLUXNET) provides a unique contribution to the study of the environmental, biological and climatological controls of net surface exchange between vegetation and the atmosphere (Baldocchi et al., 2001). Independent methods of evaluating the reliability of the eddy covariance measurements at FLUXNET sites are highly desirable. One method of independently evaluating scalar flux estimates from eddy covariance is energy balance closure. Energy balance closure, a formulation of the first law of thermodynamics, requires that the sum of the estimated latent (LE) and sensible $(H)$ heat flux be equivalent to all other energy sinks and sources

$\mathrm{LE}+H=R_{\mathrm{n}}-G-S-Q$

where $R_{\mathrm{n}}$ is the net radiation, $G$ the heat flux into the soil substrate, $S$ the rate of change of heat storage (air and biomass) between the soil surface and the level of the eddy covariance instrumentation, and $Q$ the sum of all additional energy sources and sinks. Typically, $Q$ is neglected as a small term, and an imbalance between the remaining independently measured terms on the left- and right-hand sides of Eq. (1) may indicate inaccurate estimates of scalar fluxes.

Energy balance closure is directly relevant to the evaluation of latent and sensible heat fluxes and not to other scalar fluxes (e.g. $\mathrm{CO}_{2}$ fluxes, the primary constituent for FLUXNET). However, at least four considerations make an analysis of energy balance closure at FLUXNET sites relevant and functional. First, although the source-sink distributions for water, heat and $\mathrm{CO}_{2}$ are different from each other in an ecosystem, the atmospheric transport mechanisms within and above the canopy, which are measured by eddy covariance, are similar for all scalars. Second, the computation of all scalar fluxes using the eddy covariance technique is founded on similar theoretical assumptions in the conservation equations and their Reynolds decomposition (Paw U et al., 2000). Thirdly, at FLUXNET sites all the terms in Eq. (1) are typically measured and recorded continuously at a high temporal resolution, providing a data set for independently evaluating eddy covariance fluxes across multiple time scales. Finally, an independent evaluation of energy balance closure across FLUXNET sites is useful for its own purposes, especially in view of the close biophysical coupling between carbon, energy and water fluxes (Collatz et al., 1991; Baldocchi and Meyers, 1998).

Historically, energy balance closure has been accepted as an important test of eddy covariance data (Anderson et al., 1984; Verma et al., 1986; Mahrt, 1998), and a number of individual sites within the FLUXNET network report energy balance closure as a standard procedure (e.g. Hollinger et al., 1999; Anthoni et al., 1999; Aubinet et al., 2000; Goldstein et al., 2000; Wilson and Baldocchi, 2000; Schmid et al., 2000). From these studies and many others, a general concern has developed within the micrometeorological community because surface energy fluxes $(\mathrm{LE}+H)$ are frequently (but not always) underestimated by about $10-30 \%$ relative to estimates of available energy $\left(R_{\mathrm{n}}-G-S\right)$. The imbalance is often present, though often to a lesser extent, even over flat, homogeneous surfaces and short vegetation (Stannard et al., 1994; Mahrt, 1998; Twine et al., 2000), which are presumably ideal conditions for the eddy covariance method.

An energy imbalance has implications on how energy flux measurements should be interpreted and how these estimates should be compared with model simulations (Liu et al., 1999; Twine et al., 2000; Culf et al., 2002). Within the FLUXNET community, the 
consequence of a possible widespread energy imbalance on the interpretation of $\mathrm{CO}_{2}$ fluxes is somewhat less certain and is dependent on the mechanisms creating the imbalance. General hypotheses have been suggested to account for the lack of energy balance closure, including: (1) sampling errors associated with different measurement source areas for the terms in Eq. (1), (2) a systematic bias in instrumentation, (3) neglected energy sinks, (4) the loss of low and/or high frequency contributions to the turbulent flux and (5) neglected advection of scalars. If the energy imbalance results from different measurement source areas for the terms in Eq. (1), or bias errors in net radiation, or neglected energy sinks and sources, there may be no reason to suspect that the measured $\mathrm{CO}_{2}$ fluxes are systematically inaccurate. However, if the mechanisms creating the imbalance result from inappropriate assumptions made from the scalar conservation equation, such as neglecting mean advection (Paw $\mathrm{U}$ et al., 2000), or result from low or high frequency loss of flux, the estimated $\mathrm{CO}_{2}$ flux may contain similar errors in relation to the actual terrestrial exchange. An overall evaluation of site characteristics and meteorological conditions associated with the energy imbalance may provide circumstantial evidence for its cause, and also suggest whether similar errors are likely in the $\mathrm{CO}_{2}$ flux estimates.

Because of the large geographic and biological variability at the contributing sites, FLUXNET offers a unique data set to compare energy balance closure for different vegetation types, terrain features and climates. Previous studies have focused on energy balance closure at multiple sites (Stannard et al., 1994; Barr et al., 1994; Aubinet et al., 2000; Twine et al., 2000), but FLUXNET encompasses a larger quantity of sites and with extensive variability in site characteristics. Although diverse instrumentation and processing methods in FLUXNET increase the possible sources affecting energy balance closure, instrumentation differences also present an opportunity to examine the effect of available techniques, especially potential differences between open and closed path infrared gas analyzers (IRGAs). Because FLUXNET sites typically measure continuously over annual cycles, an evaluation of closure over different seasons is possible, which has not generally been reported in other synthesis studies of energy balance closure (Stannard et al., 1994; Mahrt, 1998; Twine et al., 2000).
The goals of this study are: (1) to evaluate energy balance closure at all FLUXNET sites, and (2) to evaluate the potential source of differences in the imbalance within and between sites. Based on these considerations, (3) we will also discuss the relationship between energy balance closure and the consequences for interpreting $\mathrm{CO}_{2}$ fluxes.

\section{Materials and methods}

Methodology and review papers for many of the FLUXNET eddy covariance sites are published in Aubinet et al. (2000) and Baldocchi et al. (2001). Eddy covariance and the supporting environmental and meteorological data were contributed by individual investigators to the FLUXNET database at Oak Ridge National Laboratory's Data Archive Center. The data set contains annual files of half-hourly flux and meteorological data at eddy covariance stations across Europe and North America (Table 1) and includes a range of vegetation types and climates. A 'site-year' was accepted for analysis if more than $10 \%$ of the half-hours (approximately 1750 half-hours) in a year contained non-missing values for each of the following: net radiation $\left(R_{\mathrm{n}}\right)$, ground heat flux $(G)$, canopy heat storage $(S)$, latent heat (LE) flux and sensible heat flux $(H)$. Because the importance of canopy heat storage is expected to be small in short canopies with minimal biomass, half-hourly data were still accepted for analysis when canopy heat storage was missing, provided that the vegetation height was less than $8 \mathrm{~m}$. However, the canopy heat storage requirement was maintained for tall, forested sites because of its potential importance (McCaughey, 1985; Moore and Fisch, 1986), which eliminated several sites in this analysis. Twenty-two FLUXNET sites and 50 site-years (out of 90 available) met these requirements and were evaluated for energy balance closure. The mean energy balance data coverage (the percent of all half-hours with all energy balance terms) of the accepted site-years was $48 \%$, ranging from 11 to $90 \%$. Either because of protocol or instrument malfunctions, a number of the 'site-years' do not include data uniformly distributed throughout the year. Table 1 also contains a qualitatively brief description of terrain for each site that was available from the FLUXNET data archive. 
Table 1

Summary of the FLUXNET sites in this analysis ${ }^{\mathrm{a}}$

\begin{tabular}{lllllll}
\hline Location & Country & Vegetation & Height & Max LAI & Terrain & IRGA \\
\hline Atqasuk, AK & United States & Tundra & 0.5 & 1.5 & Flat & O \\
Blodgett, CA & United States & Conifer & 4 & 7.8 & Flat & C \\
Bondville, IL & United States & Agriculture & 2 & 6 & Flat & O \\
Barrow, AK & United States & Tundra & 0.3 & 1.5 & Flat & O \\
Happy Valley, AK & United States & Tundra & 0.3 & 1.5 & Gentle slope & O \\
Little Washita, OK & United States & Rangeland & 1 & 2.5 & Flat & O \\
Metolius, OR & United States & Conifer & 20 & 1.5 & Hilly & O \\
Niwot Ridge, CO & United States & Conifer & 20 & 4.2 & Hilly & C \\
Ponca, OK & United States & Agriculture & 1 & 5.3 & Flat & C/H \\
Shidler, OK & United States & Grassland & 0.7 & 2.8 & Flat & C/H \\
Sky Oaks, CA & United States & Chaparral & 2 & 3.0 & Hilly & O \\
Sky Oaks, CA & United States & Chaparral & 0.5 & 1.1 & Hilly & O \\
Walker Branch, TN & United States & Deciduous forest & 26 & 5.5 & Hilly & O \\
Aberfeldy & United Kingdom & Conifer & 6 & 8 & Gentle slope & C \\
Bordeaux & France & Conifer & 18 & 5.5 & Flat & C \\
Brasschaat & Belgium & Conifer & 22 & 3 & Flat & C \\
Castelporziano & Italy & Evergreen & 13 & 3.5 & Flat & 3 \\
Loobos & Netherlands & Conifer & 15 & 3 & Flat & C \\
Norunda & Sweden & Mixed conifer & 25 & 5 & Flat & 2 \\
Tharandt & Germany & Conifer & 28 & 6 & Gentle slope & C \\
Vielsalm & Belgium & Mixed forest & 32 & 4.5 & $3 \%$ slope & C \\
Bayreuth & Germany & Conifer & 19 & 5 & Hilly & C \\
\hline
\end{tabular}

a 'Height', 'Max LAI' and 'Yrs' are the vegetation height $(\mathrm{m})$, maximum leaf area index of the vegetation and the number of years with data. ' $\mathrm{O}$ ' denotes an open path system used for measuring both water and $\mathrm{CO}_{2}$ fluxes, a ' $\mathrm{C}$ ' denotes a closed path system used for measuring both water and $\mathrm{CO}_{2}$ fluxes, and ' $\mathrm{C} / \mathrm{H}$ ' denotes that a closed path IRGA used for measuring $\mathrm{CO}_{2}$ fluxes and a krypton hygrometer used for measuring water vapor.

Energy balance closure was evaluated for each site-year using four different methods. The first method, and the principal method discussed in this study, was to derive linear regression coefficients (slope and intercept) from the ordinary least squares (OLSs) relationship between the half-hourly estimates of the dependent flux variables $(\mathrm{LE}+H)$ against the independently derived available energy $\left(R_{\mathrm{n}}-G-S\right.$; see Eq. (1)). Ideal closure is represented by an intercept of zero and slope of 1 . The OLS regression is technically valid only if there are no random errors in the independent variable (Meek and Prueger, 1998), which would incorrectly imply that the measurements of $R_{\mathrm{n}}, G$ and $S$ contain no random errors. Two alternative methods were used to address the effects of this random error on the linear regression statistics (Meek and Prueger, 1998). The reduced major axis (RMA) method switches the independent and dependent variables and evaluates the slope as the geometric mean of the OLS and switched regressions. A second alternative method used to account for random errors in available energy was the method of moments (MMs), which requires that the random error in $R_{\mathrm{n}}-G-S$ be specified. Because the random error is associated with instrumentation, sampling methods and natural variability, this error is unknown and variable between sites. Therefore, several hypothetical error estimates $(10,20,40$ and $50 \%)$ were used in the MM approach to evaluate the possible effect of random error on the linear regression slope. A fourth method to evaluate closure was to cumulatively sum $R_{\mathrm{n}}-G-S$ and $\mathrm{LE}+H$ over specified time periods, such as over an entire year or during nocturnal periods, and calculate the energy balance ratio (EBR) (Mahrt, 1998; Gu et al., 1999)

$\mathrm{EBR}=\frac{\sum(\mathrm{LE}+H)}{\sum\left(R_{\mathrm{n}}-G-S\right)}$

The advantage of EBR is that it gives an overall evaluation of energy balance closure at longer time scales by averaging over random errors in the half-hour measurements. A disadvantage of EBR is the potential to 
overlook biases in the half-hourly data, such as the tendency to overestimate positive fluxes during the day and underestimate negative fluxes at night (Blanken et al., 1998; Mahrt, 1998).

\section{Results}

\subsection{Overall energy balance closure}

Regression coefficients of LE $+H$ against $R_{\mathrm{n}}-G-$ $S$, using OLSs on all the half-hour data for each of the 50 site-years, are shown in Table 2. The slope was less than 1 for all site-years, ranging from 0.53 to 0.99 , with a mean of $0.79 \pm 0.01$. The intercept ranged from -32.9 to $36.9 \mathrm{~W} \mathrm{~m}^{-2}$, with a mean of $3.7 \pm 2.0 \mathrm{~W} \mathrm{~m}^{-2}$. There were more positive (31) than negative intercepts (19). The mean coefficient of determination $\left(r^{2}\right)$ was 0.86 , ranging from 0.64 to 0.96 .

Using the RMA approach, which accounted for random errors in available energy, increased the mean slope to $0.83 \pm 0.01$. The increase in slope ranged from 2 to $10 \%$ for 43 of the 50 site-years (not shown). The remaining seven site-years increased by more than $10 \%$, with one site increasing by $25 \%$. The sites with the largest increase in slope using the RMA approach had the lowest correlation $\left(r^{2}\right.$ values less than 0.80). The mean intercept using the RMA method was slightly less than using the OLS method $\left(-1.4 \pm 1.8 \mathrm{~W} \mathrm{~m}^{-2}\right)$.

A second method to account for random errors in the independent variable was the MMs approach. The MM approach requires a quantitative estimate of the random error in the measurement of the independent variable $\left(R_{\mathrm{n}}-G-S\right)$. Setting hypothetical estimates of the random error in $R_{\mathrm{n}}-G-S$ of $10,20,40$ and $50 \%$ resulted in mean slopes of $0.78,0.82,0.99$ and 1.17 , respectively. Random errors of greater than $20 \%$ in available energy would be required for substantial improvements in energy balance closure. The mean intercept of the site-years decreased as the random error increased: $2.7 \mathrm{~W} \mathrm{~m}^{-2}$ (for a $10 \%$ random error), $-0.4 \mathrm{~W} \mathrm{~m}^{-2}$ (20\%), $-16.3 \mathrm{~W} \mathrm{~m}^{-2}$ (40\%) and $-33.5 \mathrm{~W} \mathrm{~m}^{-2}(50 \%)$.

The bias in the energy imbalance is still evident at most sites when it is evaluated as the annual ratio of total annual turbulent heat flux to available energy (i.e. annual value of EBR, Table 2). The mean EBR for
Table 2

Ordinary linear regression (OLR) coefficients for energy balance closure for all site-years $^{\mathrm{a}}$

\begin{tabular}{|c|c|c|c|c|}
\hline$n$ & Intercept & Slope & $r^{2}$ & EBR \\
\hline 5129 & 3.5 & 0.55 & 0.80 & 0.56 \\
\hline 3771 & 7.1 & 0.58 & 0.87 & 0.70 \\
\hline 3324 & 16.8 & 0.60 & 0.64 & 0.77 \\
\hline 3495 & 20.9 & 0.62 & 0.74 & $\mathrm{~b}$ \\
\hline 6197 & 29.7 & 0.64 & 0.74 & 0.82 \\
\hline 6144 & -10.1 & 0.65 & 0.83 & 1.00 \\
\hline 8738 & -0.8 & 0.68 & 0.85 & 0.68 \\
\hline 14418 & -0.7 & 0.69 & 0.85 & 1.20 \\
\hline 11459 & 2.5 & 0.70 & 0.84 & 0.72 \\
\hline 10227 & 6.0 & 0.70 & 0.83 & 0.74 \\
\hline 9267 & -12.3 & 0.71 & 0.87 & 1.03 \\
\hline 7952 & -18.3 & 0.72 & 0.86 & 0.59 \\
\hline 9621 & -6.9 & 0.72 & 0.86 & 0.66 \\
\hline 3918 & 12.7 & 0.73 & 0.92 & 0.84 \\
\hline 10712 & -32.9 & 0.73 & 0.80 & 0.39 \\
\hline 11267 & 7.7 & 0.74 & 0.88 & 0.82 \\
\hline 12727 & 36.9 & 0.74 & 0.76 & 1.00 \\
\hline 13834 & 11.3 & 0.75 & 0.84 & 0.86 \\
\hline 14468 & 9.6 & 0.75 & 0.85 & 0.88 \\
\hline 11561 & 8.4 & 0.75 & 0.86 & 0.83 \\
\hline 9649 & 31.1 & 0.75 & 0.89 & 1.16 \\
\hline 12016 & 3.1 & 0.75 & 0.88 & 0.78 \\
\hline 9005 & 16.6 & 0.76 & 0.92 & 0.88 \\
\hline 11789 & -6.0 & 0.77 & 0.83 & 0.76 \\
\hline 11058 & -16.2 & 0.78 & 0.81 & 0.53 \\
\hline 4032 & 2.6 & 0.78 & 0.87 & 0.81 \\
\hline 4039 & -5.4 & 0.79 & 0.85 & 0.62 \\
\hline 4181 & 4.5 & 0.80 & 0.88 & 0.87 \\
\hline 6848 & -8.7 & 0.82 & 0.83 & 0.69 \\
\hline 3846 & 16.3 & 0.83 & 0.92 & 0.93 \\
\hline 4370 & 5.0 & 0.83 & 0.89 & 0.79 \\
\hline 4896 & 7.4 & 0.84 & 0.96 & 0.93 \\
\hline 14760 & 6.4 & 0.85 & 0.92 & 0.97 \\
\hline 4150 & 4.1 & 0.85 & 0.85 & 0.92 \\
\hline 12751 & -1.2 & 0.85 & 0.90 & 0.84 \\
\hline 5193 & -12.5 & 0.85 & 0.95 & 0.73 \\
\hline 15638 & -5.3 & 0.85 & 0.87 & 0.69 \\
\hline 2594 & -2.1 & 0.85 & 0.94 & 0.83 \\
\hline 13891 & 2.6 & 0.86 & 0.90 & 0.89 \\
\hline 14198 & -7.7 & 0.86 & 0.91 & 1.00 \\
\hline 6357 & 28.6 & 0.87 & 0.86 & 1.09 \\
\hline 3850 & 3.6 & 0.89 & 0.90 & 0.93 \\
\hline 3864 & 6.6 & 0.89 & 0.87 & 0.34 \\
\hline 14324 & 8.9 & 0.90 & 0.91 & 1.69 \\
\hline 7993 & -18.7 & 0.90 & 0.89 & 0.79 \\
\hline 12064 & 31.5 & 0.91 & 0.91 & 1.17 \\
\hline 14545 & -15.2 & 0.92 & 0.92 & 0.77 \\
\hline 13655 & 7.1 & 0.95 & 0.91 & 0.89 \\
\hline 4670 & -23.8 & 0.97 & 0.90 & 0.71 \\
\hline 1883 & 32.6 & 0.99 & 0.79 & b \\
\hline
\end{tabular}

a 'EBR' refers to the annual ratio of $(H+\mathrm{LE}) /\left(R_{\mathrm{n}}-G-S\right)$; $n$ is the number of half-hours.

${ }^{\mathrm{b}}$ A spurious EBR ratio because the summed available energy was close to zero. 
all the site-years was 0.84 , ranging from 0.34 to 1.69 . The ratio of total turbulent heat flux to total available energy across all 50 site-years was similar, 0.82.

\subsection{Role of canopy and ground heat storage}

Twenty-six site-years with tall vegetation (height $>$ $8 \mathrm{~m}$ ) reported an estimate of canopy heat storage $(S)$. Including $S$ in the regressions for these sites increased the slope of the OLS regression by an average of $7 \%$, which is why forested sites were required to report $S$ in this study. The mean intercept decreased from 2.1 to $-0.8 \mathrm{~W} \mathrm{~m}^{-2}$. Soil heat flux $(G)$ increased the average OLS slope for grasslands, agricultural and chaparral sites by about $20 \%$. Soil heat flux had much less impact at the forested sites, where the average OLS slope increased by only $3 \%$.

\subsection{Vegetation type, vegetation height and IRGA type}

Fig. 1 shows the slope of the OLS regression against vegetation height, differentiating between sites using open and closed path IRGAs. There were no obvious differences in the slope for sites using the open and closed path designs. There was also no obvious effect of vegetation height on the OLS slope.

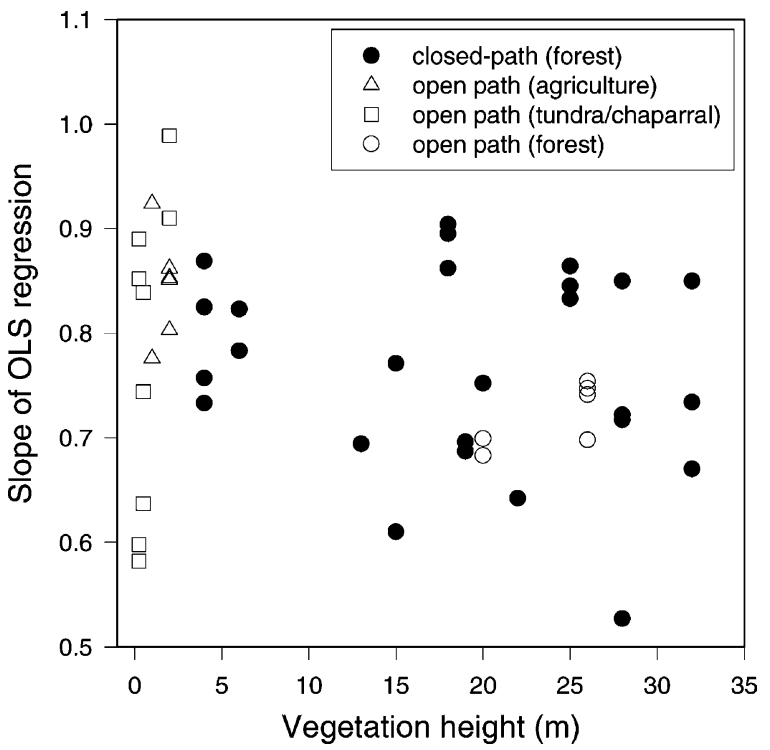

Fig. 1. The slope of the OLS regression against vegetation height for sites using closed (closed symbols) and open (open symbols) path IRGAs. Symbol shapes represent different vegetation types.

\subsection{Diurnal variation in closure}

The OLS regression statistics during periods of positive net radiation (not shown) were similar to the statistics using all the data that are shown in Table 2. The mean slope was $0.80 \pm 0.02$, ranging from 0.56 to 0.97 . The mean intercept was $-0.3 \pm 3.0 \mathrm{~W} \mathrm{~m}^{-2}$ and $r^{2}$ was 0.81 . The 'site-year' mean annual EBR during 'daytime' periods was 0.80 , and EBR was equal to or greater than 1 at only two site-years. The ratio of total daytime turbulent heat flux to total daytime available energy for all 50 site-years was similar, 0.79.

The mean OLS slope during nighttime periods (net radiation less than zero) was only $0.35 \pm 0.03$, ranging from -0.04 to 0.69 . The mean intercept was $-5.5 \pm 1.4 \mathrm{~W} \mathrm{~m}^{-2}$ and the correlation was typically weak (mean $r^{2}=0.11$ ). In some cases, the 'site-year' annual nocturnal EBR was negative or was much less or much greater than 1 . The ratio of total turbulent flux to the total available energy summed over all the sites was 0.54 during the night, which is less than during the day. The magnitude of the imbalance at night was strongly dependent on turbulent mixing, as shown in the following section.

Data from all the site-years were combined to compute the diurnal course of the EBR. For each of the $24 \mathrm{~h}$ the half-hourly $\mathrm{LE}+H$ and $R_{\mathrm{n}}-G-S$ were summed over entire site-years using the entire data set. The ratio between these two sums (Eq. (1)) was the hourly EBR. Fig. 2 shows the diurnal course of the EBR, along with the mean magnitudes of $\mathrm{LE}+H$ and $R_{\mathrm{n}}-G-S$. During morning and evening transition periods, when the mean value of $R_{\mathrm{n}}-G-S$ was close to zero, the EBR is not especially meaningful. Between these two transition periods there was a general increase in the EBR from the morning to afternoon. This pattern of a greater EBR in the afternoon relative to the morning was observed in both the warm and cold seasons and was typical for most of the individual site-years (not shown).

\subsection{Effect of turbulent mixing}

The effect of turbulent mixing was evaluated between and within sites by analyzing closure with respect to friction velocity. The slope of the OLS regression was not a function of the mean annual friction velocity across all the site-years (not shown). 


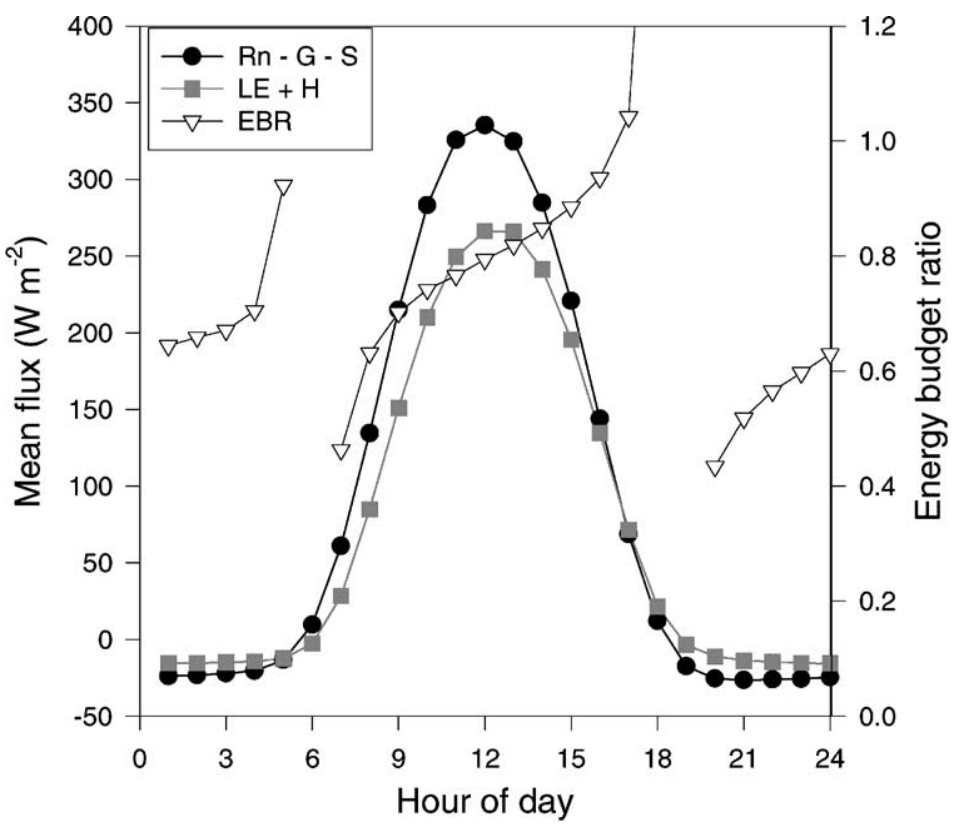

Fig. 2. The mean diurnal energy budget ratio (EBR) using all the site-years in this study. Also shown are the mean diurnal values of $R_{\mathrm{n}}-G-S$ and $\mathrm{LE}+H$.

The effect of friction velocity was also evaluated within each of the site-years. Friction velocity typically changes with stability and time of day. Therefore, the change in energy balance closure between night and day (shown above) could also be the direct result of changes in friction velocity. Nevertheless, a simple method was used to partially isolate the effects of friction velocity from the effects of time of day (and presumably to some extent, stability). Data for each of the site-years were separated into 48 groups, representing the 48 half-hours in a day. The data in each of the 48 groups were segregated into two large groups, each containing half the data. One group contained data when the friction velocity was above the annual median for that half-hour, and the second group contained data when the friction velocity was below the annual median for that half-hour. OLS regressions were performed for both groups of half-hour data for each site-year.

The slope was typically greater when the friction velocity was above the half-hourly medians, but the intercept was slightly less. The mean slope for all site-years was 0.73 when the friction velocity was below the median, with an intercept of 7.1 and $r^{2}=$
0.86 . Above the median friction velocity, the slope was 0.81 , with intercept of 1.0 and $r^{2}=0.87$. The slope was significantly $(P<0.05)$ greater for data above the mean friction velocity in 41 of the 50 site-years. A similar result was obtained when data were separated into five friction velocity categories instead of two, but the largest differences were between the lowest friction velocity groups. The OLS slope increased from 0.69 for winds in the lowest $20 \%$ to $0.73,0.77$, 0.80 and 0.80 in the four remaining groups.

The effect of friction velocity on energy balance closure was analyzed separately for daytime and nighttime data using the same methods that were just described using all the data. For both daytime and nighttime, data from each site-year were segregated by friction velocity into five percentile groups (five sets, each with $20 \%$ of the site-year data). There was a very weak trend $\left(r^{2}=0.08\right)$ for the OLS slope to increase with friction velocity during daytime hours (Fig. 3a). A slightly more obvious trend was evident when EBR was plotted against friction velocity $\left(r^{2}=0.14\right)$ (Fig. 3b).

The OLS slope was smaller and was more dependent $\left(r^{2}=0.43\right)$ on friction velocity during nocturnal 

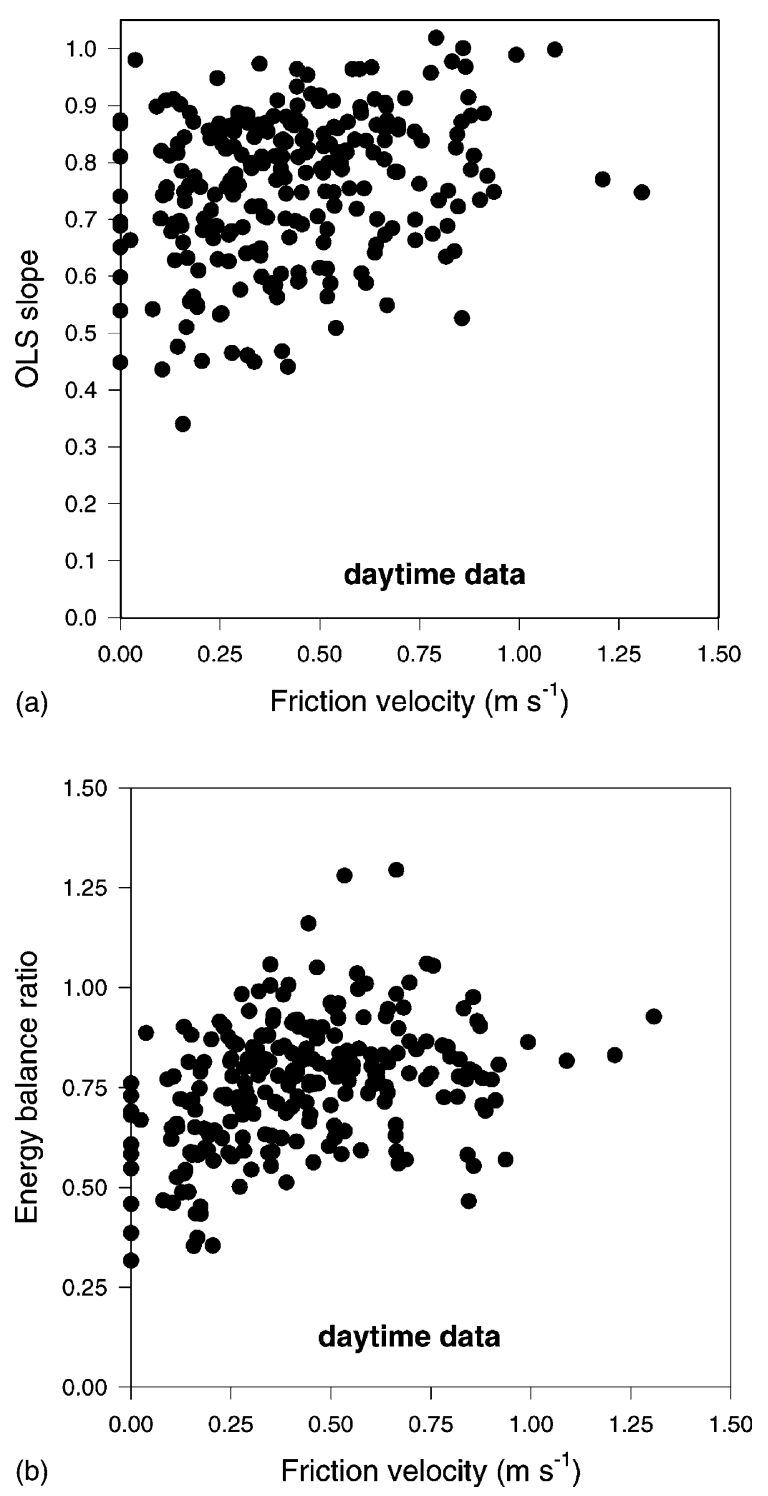

Fig. 3. The (a) OLS slope and (b) EBR against friction velocity during daytime periods. Each site-year is represented by five points on these plots, representing data sorted by friction velocity into five 20 percentile groups of half-hour data. The points showing a friction velocity of zero are the result of an inadequate number of significant figures in the FLUXNET data archive.

periods than during the daytime (Fig. 4). When the mean friction velocity was below $0.25 \mathrm{~m} \mathrm{~s}^{-1}$, the slope of the OLS regression was less than 0.50 for all site-years. When the mean friction velocity exceeded $0.50 \mathrm{~m} \mathrm{~s}^{-1}$ the slope was greater, but was still typically less than 1.0.

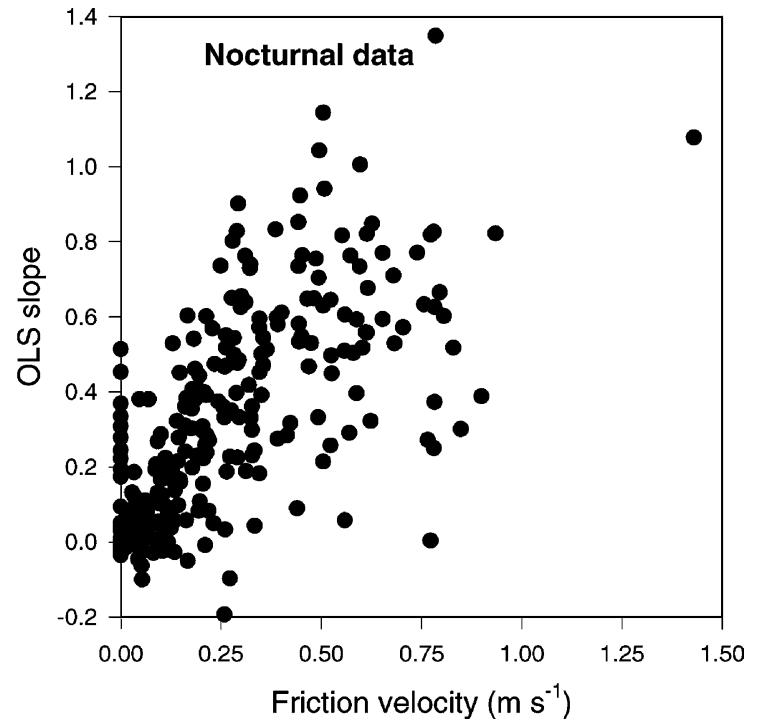

Fig. 4. The OLS slope against friction velocity $\left(u_{*}\right)$ during nocturnal periods (net radiation less than zero). Each site-year is represented by five points, representing data sorted by friction velocity into five 20 percentile groups of half-hour data.

Fig. 5 shows the effect of friction velocity on the OLS slope during nocturnal periods in more detail at specific FLUXNET sites. The sites shown in Fig. 5 represent a range of vegetation types, IRGA types and terrain. The nocturnal OLS slope usually increased with friction velocity within (Fig. 4) and across (Fig. 5) sites, but the mean $r^{2}$ was only 0.15 , ranging from 0.00 to 0.51 . In some cases the slopes were not statistically different from zero, or the intercept changed perceptibly with friction velocity. To help address this issue, the effect of friction velocity on nighttime closure was also analyzed using the EBR method (Fig. 6). The general relationship between EBR and friction velocity was similar to that using the OLS slope (increasing with friction velocity), except EBR often exceeded 1 at high friction velocities.

\subsection{Effects of seasonality and the Bowen ratio}

Nineteen site-years had sufficient data within all months of the year to analyze seasonality in energy balance closure. Within each of these 19 site-years, data was segregated into six 2-month increments, and OLS regressions were performed for each 2-month period. Fig. 7 shows the OLS slope of the six 2-month 

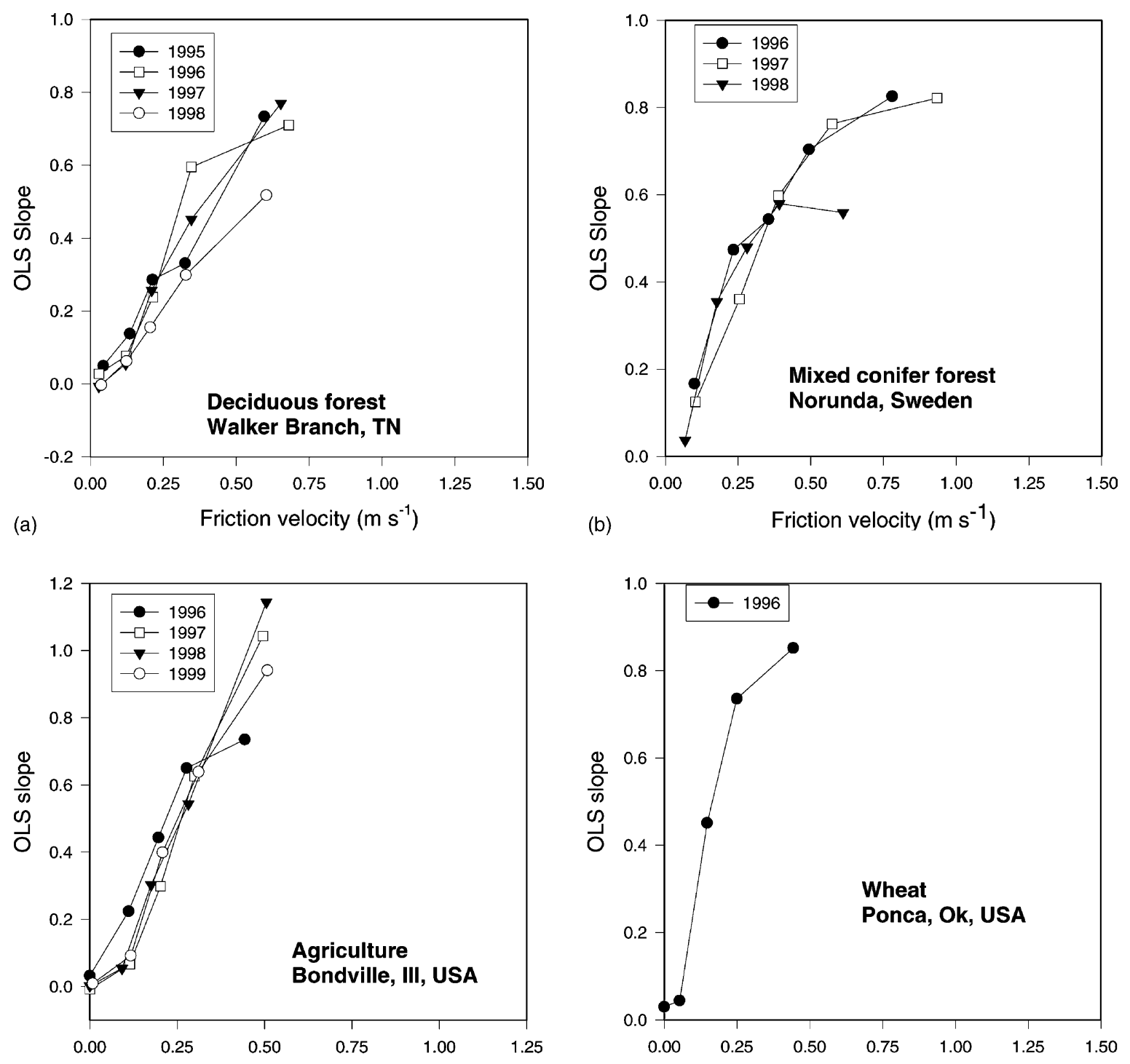

(c)

Friction velocity $\mathrm{m} \mathrm{s}^{-1}$

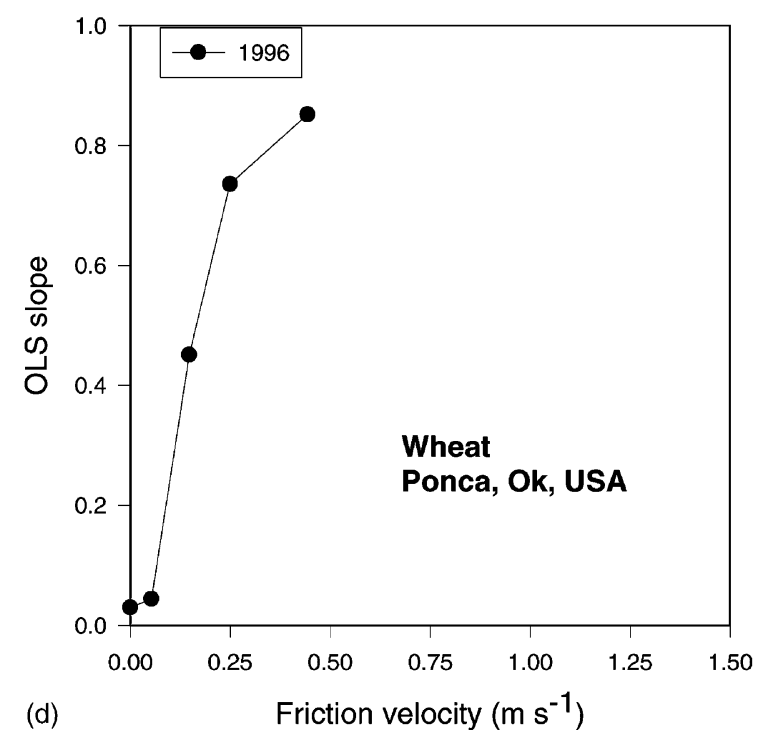

Fig. 5. The OLS slope against friction velocity for four contrasting FLUXNET sites during nocturnal periods.

increments for each site-year, with the line depicting the mean of all site-years. All sites are in the Northern Hemisphere and the mean slope increased from winter to summer months, averaging 0.66 in January and February to 0.80 in July and August. The mean intercept was also lower in winter $\left(-3.5 \mathrm{~W} \mathrm{~m}^{-2}\right)$ than in summer $\left(4.0 \mathrm{~W} \mathrm{~m}^{-2}\right)$. The coefficient of determination $\left(r^{2}\right)$ ranged from 0.68 to 0.89 and was generally larger in summer than in winter. The EBR method indicated smaller differences between seasons (not shown), with the mean ratio ranging from only 0.81 to 0.87 , with the exception of first 2-month period (January and February) when the mean ratio was 0.72 . Total available energy, and the denominator in the EBR calculations, was an order of magnitude greater in the peak summer period relative to the winter period.

Data were also analyzed to determine if the energy imbalance varied with Bowen ratio. For each of the 50 


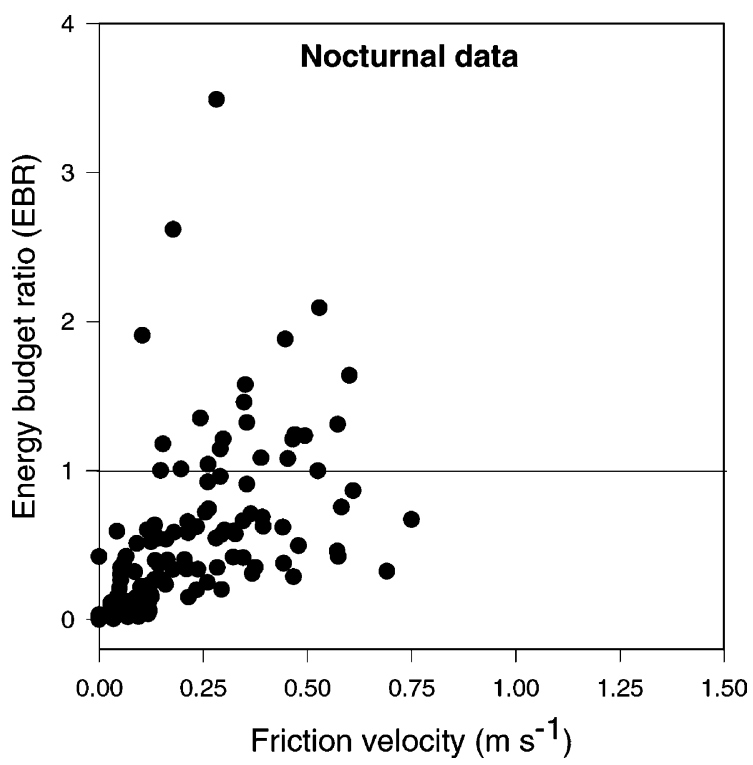

Fig. 6. EBR against friction velocity $\left(u_{*}\right)$ during nocturnal periods (net radiation less than zero). Each site-year is represented by five points, representing half-hour data sorted by friction velocity into five 20 percentile groups. site-years, the daytime data were segregated by Bowen ratio into four percentile groups, with the requirement that both $H$ and LE exceed $10 \mathrm{~W} \mathrm{~m}^{-2}$ to avoid periods of very small fluxes. For each of the sites, the Bowen ratio changed by nearly an order of magnitude between the first and last percentile groups. No overall trend in the OLS slope with Bowen ratio was observed for the sites. Isolating sites with closed path sensors, the mean slope was least in the lowest Bowen ratio category ( 0.67 versus 0.77 for other categories) (Fig. 8a); isolating sites with open path sensors, the mean slope was least for the highest Bowen ratio category $(0.67$ versus 0.74 for other categories) (Fig. 8b). The mean intercept decreased with Bowen ratio for sites employing the open path sensors and increased with Bowen ratio for sites using the closed path sensors. The EBR did not change with Bowen ratio for either closed or open path sensors.

\subsection{Link between energy balance closure and $\mathrm{CO}_{2}$ fluxes}

To evaluate a possible link between the energy imbalance and the fluxes of $\mathrm{CO}_{2}$, data for each site-year were sorted into three groups based on the normalized

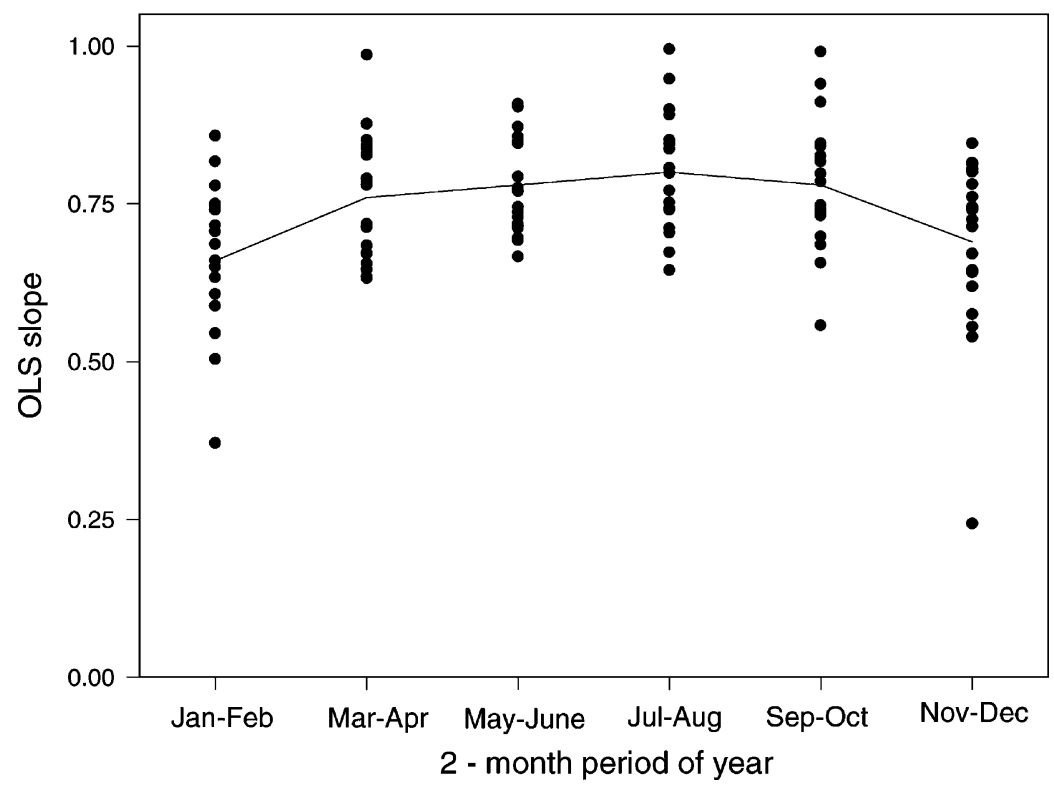

Fig. 7. The OLS slope, evaluated over 2-month increments, for the 19 site-years that had data over the entire annual cycle. The line shows the mean for the 2-month increments. 

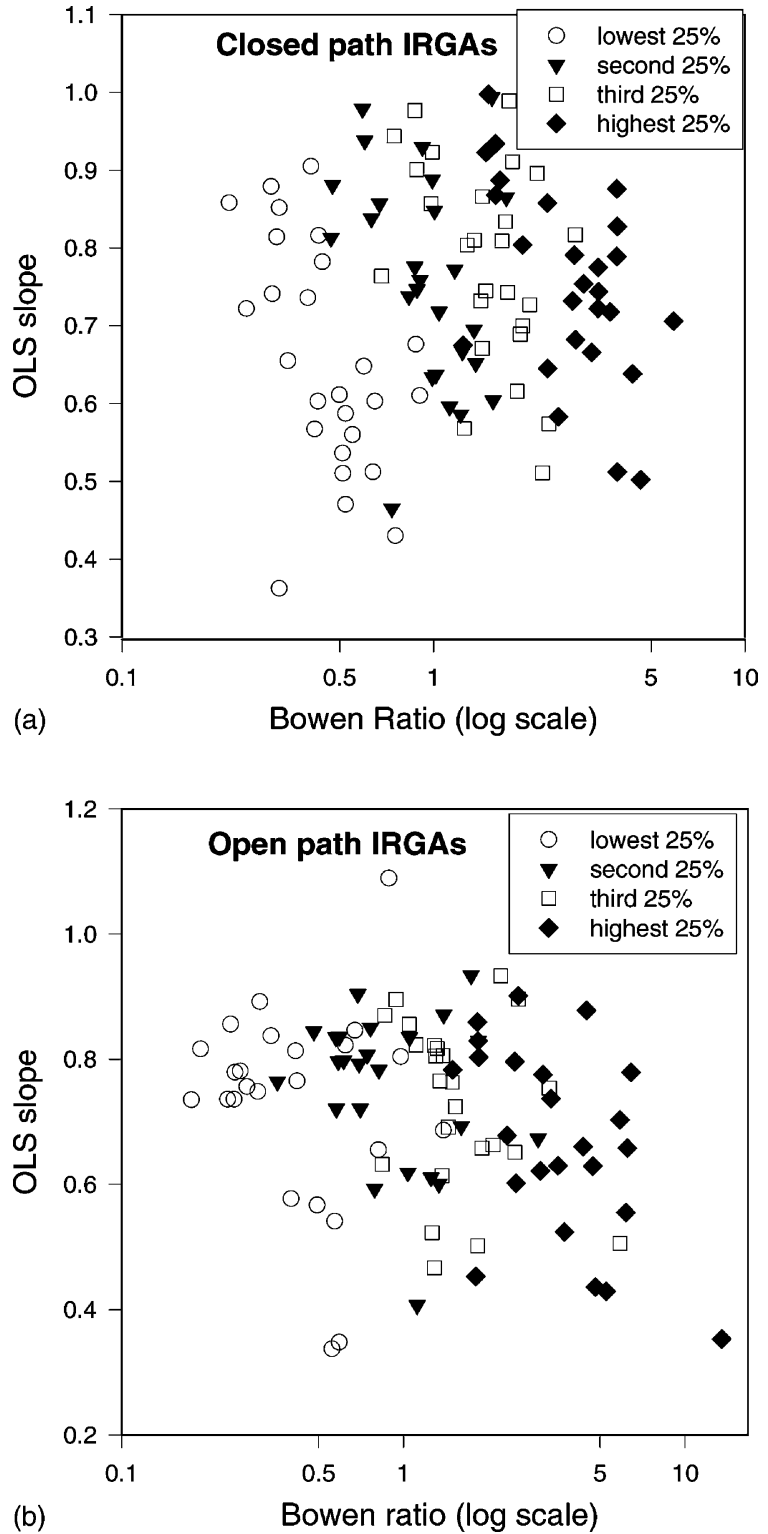

Fig. 8. The OLS slope versus Bowen ratio for site-years with (a) closed and (b) open path IRGAs. Daytime half-hour data was segregated into four 25 percentile groups for each site.

residual in the energy imbalance $\left(\delta_{\mathrm{e}}\right)$

$\delta_{\mathrm{e}}=\frac{R_{\mathrm{n}}-G-S-\mathrm{LE}-H}{R_{\mathrm{n}}-G-S}$

One group (labeled 'AC' for 'acceptable closure') contained only half-hourly data when energy balance closure was 'acceptable' $\left(\left|\delta_{\mathrm{e}}\right| \leq 0.10\right)$. The second group (labeled 'LF' for 'low fluxes') contained data when $\delta_{\mathrm{e}}>0.10$ (turbulent heat fluxes underestimated relative to available energy) and the third group (labeled 'HF' for 'high fluxes') contained data when $\delta_{\mathrm{e}}<0.10$ (turbulent heat fluxes overestimated relative to available energy). Daytime data, defined by photosynthetically active radiation (PAR) $>0$, was further segregated into five sub-groups based on PAR $(50<$ PAR $<300 ; 300<$ PAR $<600 ; 600<$ PAR < 1000; $1000<$ PAR < 1500; PAR > 1500) (units of PAR in $\mu \mathrm{mol} \mathrm{m}^{-2} \mathrm{~s}^{-1}$ ). To avoid spurious ratios, half-hour data was not included in this analysis if $R_{\mathrm{n}}+G+S<20 \mathrm{~W} \mathrm{~m}^{-2}$. Only data between day 160 and day 240 (mostly summer season) were used to limit the analysis to periods when assimilation and $\mathrm{CO}_{2}$ uptake are important and when PAR is expected to be a forcing variable for $\mathrm{CO}_{2}$ fluxes. Therefore, this evaluation only applies to the warm season.

Fig. 9 shows the mean $\mathrm{CO}_{2}$ flux (negative values indicate uptake by vegetation) for each of the five

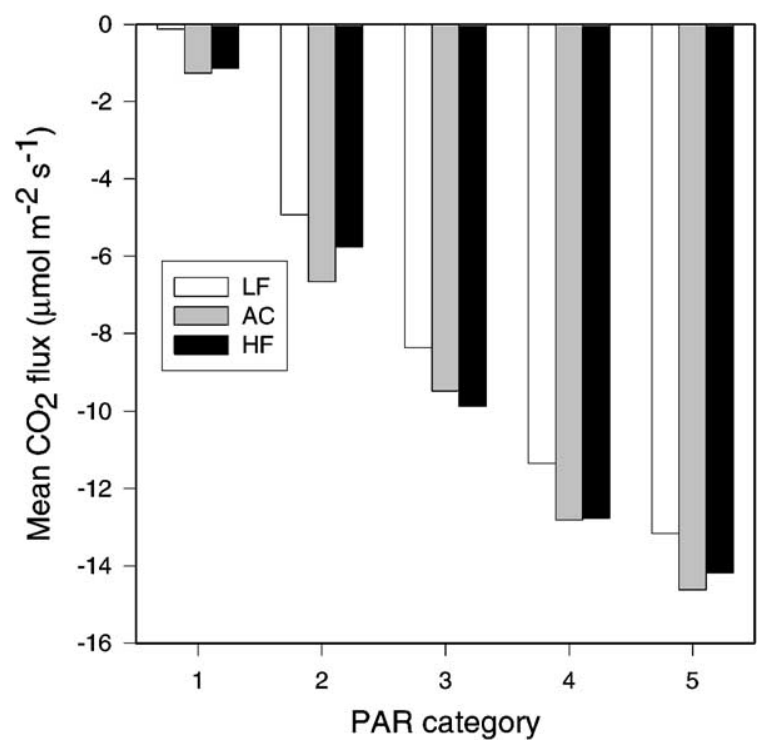

Fig. 9. The mean $\mathrm{CO}_{2}$ flux between days 160 and 240 across all available site-years for the five PAR groups (see text). Data was segregated into one of the three groups based on energy balance closure (LF for low turbulent energy fluxes relative to available energy; $\mathrm{AC}$ for acceptable closure and $\mathrm{HF}$ for high turbulent energy fluxes relative to available energy). The means shown were estimated after estimating each of the site-year means (i.e. each site-year contributed equally). 
Table 3

The results of the $t$-test to check for significant differences in the mean $\mathrm{CO}_{2}$ flux with energy balance closure for each of the five PAR categories (see text) $)^{\mathrm{a}}$

\begin{tabular}{lllllll}
\hline PAR group & LF $<$ AC & NS & LF $>$ AC & HF $<$ AC & NS & HF $>$ AC \\
\hline PAR 1 & 12 & 14 & 2 & 2 & 23 & 3 \\
PAR 2 & 18 & 15 & 2 & 9 & 25 & 1 \\
PAR 3 & 17 & 16 & 5 & 5 & 23 & 6 \\
PAR 4 & 16 & 14 & 8 & 3 & 29 & 4 \\
PAR 5 & 12 & 9 & 4 & 5 & 3
\end{tabular}

${ }^{a}$ Columns 2-4 give the number of site-years that fall within one of the three categories in the test between groups LF and $\mathrm{AC}$ ( $\mathrm{LF}<\mathrm{AC}$ : magnitude of mean $\mathrm{CO}_{2}$ flux in group LF was less (less negative) than AC; NS: not significant; $\mathrm{LF}>\mathrm{AC}$ : magnitude of mean $\mathrm{CO}_{2}$ flux in group LF greater (more negative) than in $\mathrm{AC}$ ). The last three columns show number of site-years that fall within one of the three similar categories between groups HF and AC (symbols have similar meaning as for the $t$-test between LF and AC). A $t$-test was performed only if more than 30 half-hours of data were available in the PAR/energy balance closure category.

PAR categories across all sites, differentiating between data with 'acceptable' energy balance closure $(\mathrm{AC})$ and data when turbulent heat fluxes were underestimated (LF) or overestimated (HF) relative to available energy. For all PAR categories, the magnitude of the mean $\mathrm{CO}_{2}$ was lowest (less negative) during periods when the turbulent heat fluxes were underestimated relative to available energy (group LF). Taking the mean across all PAR categories the magnitude of the $\mathrm{CO}_{2}$ flux was approximately $15 \%$ lower for group LF relative to AC. Alternatively, there was little change in the mean $\mathrm{CO}_{2}$ flux between data with $\mathrm{AC}$ and data when the imbalance occurred because of an 'overestimate' of turbulent heat fluxes relative to available energy (between groups $\mathrm{HF}$ and $\mathrm{AC}$ ).

For each site-year, a $t$-test was performed within each of the five PAR categories to determine if there were statistical differences in the mean $\mathrm{CO}_{2}$ flux across the energy imbalance groups (i.e. AC, LF, and $\mathrm{HF}$ ). Table 3 summarizes the number of site-years for groups LF and $\mathrm{HF}$ when there was not a significant difference in the mean $\mathrm{CO}_{2}$ flux relative to $\mathrm{AC}$ data for the given PAR group, and when the magnitude of the $\mathrm{CO}_{2}$ flux was either significantly $(P<0.05)$ lower or higher than data in the AC group. For each PAR group, between 42 and $48 \%$ of the site-years had a significantly lower net $\mathrm{CO}_{2}$ uptake (less negative flux) when the turbulent energy flux was underestimated compared to when the imbalance was within $10 \%$ (group LF relative to AC in Table 3). There were far fewer differences in the mean $\mathrm{CO}_{2}$ fluxes between group $\mathrm{HF}$ and $\mathrm{AC}$ (Table 3).
Nighttime data were also separated into three similar groups based on energy balance closure. The mean $\mathrm{CO}_{2}$ flux across all sites when energy balance closure was acceptable (group AC) was almost twice $\left(4.72 \mu \mathrm{mol} \mathrm{m}^{-2} \mathrm{~s}^{-1}\right)$ that compared to periods when turbulent heat fluxes were underestimated (group LF, $2.39 \mu \mathrm{mol} \mathrm{m}^{-2} \mathrm{~s}^{-1}$ ). There was no difference in the mean air temperature between these two groups of data (both were $16.2^{\circ} \mathrm{C}$ ). Of the 36 site-years with sufficient nocturnal energy balance and $\mathrm{CO}_{2}$ flux data available, the nocturnal $\mathrm{CO}_{2}$ flux was significantly greater $(P<0.05)$ in group $\mathrm{AC}$ relative to LF for 27 of the site-years. The quantity of nocturnal data in the group HF was minimal, and it was not included in the analysis.

To further demonstrate a possible link with the nocturnal carbon dioxide flux, Fig. 10 shows the relationship between ecosystem respiration at $10^{\circ} \mathrm{C}$, estimated from nocturnal data using the methods detailed by Falge et al. (2001), for two of the sites shown in Fig. 5. At the agricultural site (Fig. 10a), there appears to be a threshold friction velocity in carbon dioxide flux, although no threshold is apparent in the energy balance closure (Fig. 5c). At the forest site in Norunda, Sweden, a threshold friction velocity for carbon fluxes (Fig. 10b) and energy balance closure (Fig. 5b) is not obviously apparent.

\section{Discussion}

Although the intercepts of the OLS regressions for the site-years were typically non-zero, the OLS slope 

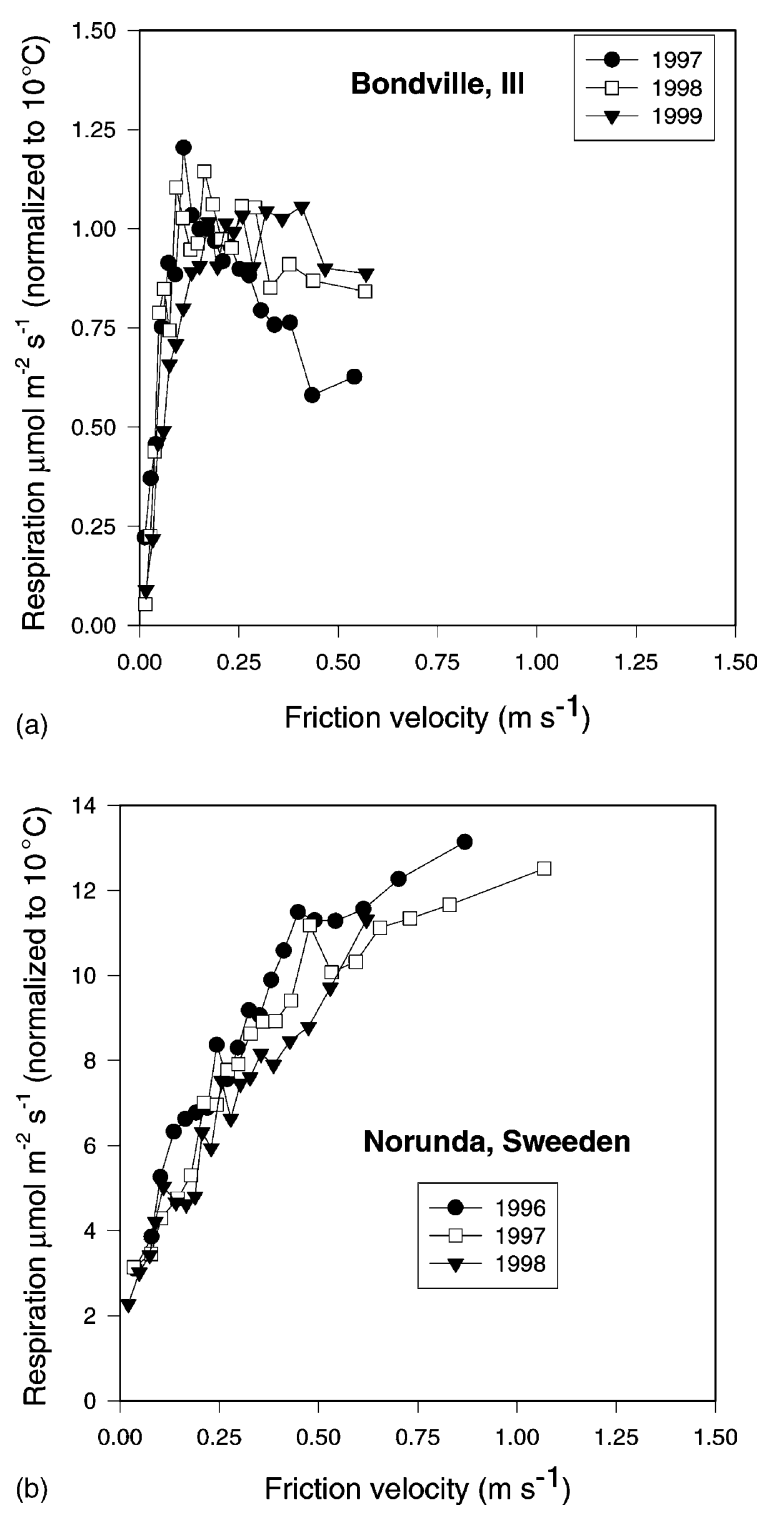

Fig. 10. The mean nocturnal respiration, normalized to $10^{\circ} \mathrm{C}$, against friction velocity sorted into 20 five percentile friction velocity groups using the method of Falge et al. (2001): (a) data from agricultural field in Bondville, IL; (b) data from a mixed forest in Norunda, Sweden.

(for positive and negative intercepts) was always less than 1 . The EBR was less than 1 for over $80 \%$ of the site-years, further suggesting a general lack of closure. The general lack of complete energy balance closure at FLUXNET sites (linear regression slope and EBR typically less than 1) is consistent with historical evidence that the energy balance is often not closed using the eddy covariance technique (Mahrt, 1998; Gu et al., 1999; Twine et al., 2000). Explanations for the imbalance have been hypothesized in previous studies (Stannard et al., 1994; Mahrt, 1998; Aubinet et al., 2000; Twine et al., 2000; Culf et al., 2002) and can generally be summarized by the list in Table 4 . This list is not totally comprehensive, but covers the primary reasons usually suspected for the energy imbalance: (1) systematic errors associated with the sampling mismatch between the flux footprint and the sensors measuring other components of the energy balance, (2) a systematic instrument bias, (3) neglected energy sinks, (4) low and high frequency loss of turbulent fluxes, and (5) horizontal and/or vertical advection of heat and water vapor. Table 4 also summarizes how these sources of error may affect energy balance closure and carbon dioxide fluxes. Each of these problems will be discussed and related to the FLUXNET data set. Errors in the eddy covariance approach are also summarized in Businger (1986) and Folken and Wichura (1996).

\subsection{Sampling errors}

Random errors associated with averaging a subset of turbulent eddies at one location to estimate ensemble mean turbulent fluxes (Moncrieff et al., 1996; Mahrt, 1998) will reduce $r^{2}$, but should not affect the OLS slope, the long-term EBR or long-term flux estimates. Accounting for random errors in the dependent variable $\left(R_{\mathrm{n}}-G-S\right)$ using two statistical approaches (Meek and Prueger, 1998) reduced the slope of the OLS regression, but the errors would need to approach $40 \%$ to obtain a mean slope of 1 across sites, and with these hypothetical errors the intercepts became highly negative. Furthermore, random errors larger than $40 \%$ are possible for $G$ and $S$ in some conditions, but they are less likely for $R_{\mathrm{n}}$, which has a larger source area and is frequently the dominant available energy term. Furthermore, the overall long-term bias in closure at most sites, indicated by the annual values of EBR, suggests a low probability that the imbalance is primarily a statistical artifact.

A second type of sampling error is associated with the inability to match the source areas of the eddy covariance measurements (the flux footprint) with the source area of the instrumentation measuring $R_{\mathrm{n}}, G$ 
Table 4

General list of possible reasons for energy imbalance at FLUXNET sites ${ }^{\mathrm{a}}$

\begin{tabular}{lllll}
\hline Cause of imbalance & Examples & $\mathrm{LE}+H$ & $R_{\mathrm{n}}-G-S$ & $\mathrm{Ratio}^{\mathrm{Affects}} \mathrm{CO}_{2}$ \\
\hline Sampling & Source areas differ & & No \\
Instrument bias & Net radiometer biased & & If sonic or IRGA \\
Neglected energy sinks & Storage above soil heat plates & & No \\
High/low frequency loss & Sensor separation/large eddies & - & - & Yes \\
Advection & Regional circulation & & Yes \\
\hline
\end{tabular}

${ }^{a}$ Also shown is whether this effect is expected to underestimate (negative sign) or overestimate (positive sign) the turbulent fluxes $(\mathrm{LE}+H)$, available energy $\left(R_{\mathrm{n}}-G-S\right)$ and the energy balance closure ratio $(\mathrm{LE}+H) /\left(R_{\mathrm{n}}-G-S\right)$. The last column indicates whether this effect is relevant to interpretations of the $\mathrm{CO}_{2}$ flux.

and $S$. Schmid (1997) provides a detailed discussion of the issues involved in matching scales of observations, particularly the different geometry and dynamics of the source areas for net radiometers and flux footprints. The source area for a net radiometer has a radius related to sensor height that is fairly constant with time and is centered below the instrument. The instrument typically protrudes horizontally off a tower, and in some cases the tower structure or removal of vegetation near the tower may influence the sensor. Alternatively, the spatial dimension of the flux footprint is not fixed in space and is dependent on atmospheric conditions, typically approximating an ellipse that is distorted in the mean upwind direction. In theory and practice, the source areas for a net radiometer and eddy covariance flux footprint never match.

The assumption of equivalent source areas is even more problematic when relating $G$ to $H$ and LE. The ground area influencing the soil heat flux plates or thermocouples (if using the calimetric method) (Buchan, 1989) is one to several orders of magnitude smaller than the associated source areas of the net radiometers and the eddy covariance flux footprint. A similar daunting problem exists for the estimate of $S$ in tall vegetation, especially the component associated with sampling biomass temperature, which is a complex function of aspect, depth into woody tissue and canopy height.

The most obvious effect on energy balance closure occurs when the measurement source area of one of the energy balance components is representative of a systematically different surface or climate than the source area sensed by the other energy balance components. This systematic error would generally be greatest in open canopies or in canopies with large gradients in biophysical characteristics, where hetero- geneity is present at multiple scales (Culf et al., 1993; Stannard et al., 1994; Baldocchi et al., 2000; Kustas et al., 2000). FLUXNET sites are not generally designed to evaluate spatial variability in the available energy components at the spatial scale of the turbulent flux footprint. However, $R_{\mathrm{n}}$ is typically the largest component of available energy and several studies have found little spatial variability of $R_{\mathrm{n}}$ above uniform (Twine et al., 2000) and complex patchy landscapes (Schmid et al., 1991; Stannard et al., 1994; Anthoni et al., 2000) (but also see Culf et al., 1993). Although measurement source errors are present at FLUXNET sites, this type of error is not expected to consistently present a positive systematic bias in available energy relative to turbulent scalar fluxes. Other studies investigating multiple sites have deduced a similar hypothesis (Stannard et al., 1994; Mahrt, 1998; Twine et al., 2000; Anthoni et al., 2000).

\subsection{Instrument biases}

A second group of errors that can affect energy balance closure involves instrument biases, inaccurate calibrations and data processing errors. These comments will focus on a few general aspects of instrumentation, because it is assumed that all sites are processing data and computing fluxes correctly. Cross calibration of instrumentation and processing methods have probably reduced some of these uncertainties between selected sites (Aubinet et al., 2000; Baldocchi et al., 2001).

Soil heat flux plates can be inaccurate because the thermal conductivity of the heat flux plate and surrounding soil may be unequal (VanLoon et al., 1998). Heat flux plates typically have a conductivity similar to soil, but thermal properties vary temporally 
because of changes in soil water content and temperature (Verhoef et al., 1996). Soil heat flux plates also can alter the environment they are measuring, especially by limiting water movement in soils (Mayocchi and Bristow, 1995). AmeriFlux sites generally use REBS (Radiation Energy Balance Systems) heat flux plates, and EUROFLUX sites use heat flux plates and calimetric methods (Aubinet et al., 2000).

Several studies have addressed calibration methods and the accuracy of various brands of net radiometers (Field et al., 1992; Halldin and Lindroth, 1992; Hodges and Smith, 1997; Stannard et al., 1994; Kustas et al., 1998; Culf et al., 2002; Halldin, 2002). Some of the differences in closure between FLUXNET sites are probably the result of bias errors in net radiometers. A majority of the Ameriflux sites have used REBS net radiometers; EUROFLUX sites have used a variety of net radiometers, with many sites using instruments manufactured by REBS and Schulze/Daeke. Bias errors up to $15 \%$ have been noted between older versions of net radiometers, which includes some of the manufactures used in FLUXNET (Field et al., 1992; Stannard et al., 1994), although the commercial instrumentation and calibration methods have been subsequently updated. Some versions of the REBS net radiometers, which are common at AmeriFlux sites, are known to have been calibrated incorrectly (Kustas et al., 1998; Twine et al., 2000), creating a low bias (15\% during the daytime) in net radiation and possibly erroneously improving energy balance closure. In fact, recent improvement in design and calibration of net radiometers appears to have increased the energy imbalance (Wilson and Baldocchi, 2000; Culf et al., 2002) Calibration procedures, either performed by the manufacturer or site operators, differ among FLUXNET sites, making it difficult to quantify bias errors. Recent inter-comparisons of independently calibrated sensors at several sites showed only small differences in sensor type (unpublished data using Didcot DRN-305 and REBS Q7 at Brasschaat, Germany, and REBS Q7 and Kipp and Zonen NR LITE at Walker Branch, TN).

Although there can be differences between types of net radiometers, nearly all the net radiometers used in FLUXNET would have to be biased high during the day and low at night to account for the energy imbalance. Twine et al. (2000) concluded that in the ARM (Atmospheric Radiation Measurement) project, which has a primary goal of accurately measuring radiation components, an energy imbalance persisted despite careful net radiation calibrations. Estimates of net radiation using independently derived satellite estimates also indicated a lack of closure across BOREAS sites (Gu et al., 1999).

Instrument errors can also occur with the eddy covariance instrumentation used to compute velocities (sonic anemometer), temperature (sonic anemometer) and water vapor (usually IRGA, either open or closed). Mounting equipment and instrumentation may shadow sonic anemometers (Wyngaard, 1981) and degrade data quality and energy balance closure in certain wind directions, but this effect does not explain the consistent lack of closure across most wind directions at the sites. A second source of error occurs when turbulent fluctuations are of insufficient magnitude to be resolved by the instrumentation (Mahrt, 1998). Errors concerning possible insufficient sampling frequency and loss of high frequency flux and other errors associated with time and space assumptions used in the eddy covariance technique are addressed subsequently.

\subsection{Other energy sinks}

An assumption in the analysis of energy balance closure is that the energy in the system can be approximated from the five measured components (LE, $H$, $R_{\mathrm{n}}, G$, and $S$ ), and that all energy stored beneath the sensor $(G$ and $S)$ is estimated properly. Even when soil heat flux plates are used, as at a number of FLUXNET sites, a heat storage term is needed to account for the soil above the sensors (Mayocchi and Bristow, 1995). In open canopies, this storage can be large even when heat plates are buried near the surface (Stannard et al., 1994; Mayocchi and Bristow, 1995), and it is assumed that this storage is correctly accounted for at the FLUXNET sites. The FLUXNET data suggests that inaccuracies in $G$ have a greater impact on energy balance closure in agricultural, chaparral and grassland sites than in forests.

A correction to the soil heat flux calculation that is commonly neglected and difficult to estimate is the 'isothermal' LE component (Buchan, 1989; Mayocchi and Bristow, 1995). If soil heat flux plates are near the surface and above the region where subsurface evaporation typically occurs, the isothermal LE flux is proportional to the subsurface evaporation beneath the heat flux plates. Published estimates of soil evap- 
oration indicate that the magnitude of this term for FLUXNET sites is probably less than $5 \%$ of $R_{\mathrm{n}}$ in closed forest canopies with dense litter layers (Wilson et al., 2000), but may be several times greater in more open canopies (Baldocchi et al., 2000) or above bare soil or bare soil covered by crops (Villalobos and Fereres, 1990). For the majority of FLUXNET sites, which use soil heat flux plates, consideration of this term will typically decrease the estimated $G$ (Mayocchi and Bristow, 1995) and increase the estimated total available energy, which may further degrade energy balance closure.

Heat storage between the soil surface and level of flux measurements $(S)$ can also be difficult to estimate, because a full accounting requires air temperature and humidity measurements at multiple heights, as well as estimates of biomass temperature. The number of temperature probes used at FLUXNET sites varies from just a few to dozens (Aubinet et al., 2000). Gradients of stem temperature, both with height and aspect in the canopy and with depth in woody tissue, can be a source of important sampling errors (Aston, 1985; Moore and Fisch, 1986). Estimating total canopy biomass is particularly challenging, and an estimate of the canopy specific heat constant is also required. Consideration of canopy heat storage generally decreased the magnitude of the imbalance at FLUXNET sites. Because of rapid temperature changes, the change in canopy heat storage $(S)$ was a greater fraction of net radiation early in the day, which is also when the mean imbalance was greater. Better energy balance closure during the afternoon, when temperature changes and $S$ are usually smaller, may be a clue that storage components are frequently underestimated at FLUXNET sites.

Careful examination of storage terms at the FLUXNET site in Bordeaux, France, dramatically improved energy balance closure (Lamaud et al., 2001) and this site has an OLS slope approaching 1 (3-year mean of 0.94). Nevertheless, the general lack of closure, even in very short and sparse vegetation, seems to suggest that canopy heat storage is not likely the only important source of imbalance across all sites. Furthermore, because storage components should nearly vanish when integrated over an annual basis, storage errors would not explain the low EBR over longer periods (i.e. site-years).

Even if each of the five components is accurately measured, additional energy sinks $(Q)$ are present in the canopy, although these are typically neglected because they are considered small. Photosynthesis is a form of biochemical energy storage that is typically in the order of $1-2 \%$ of the available energy (Oke, 1987), but may be several times greater in agricultural plants with high quantum yields, such as at the maize site in Bondville, IL.

Based on thermodynamic considerations, additional terms in the energy balance equation have been suggested by Sun et al. (1995) and Paw U et al. (2000). Along with other small correction terms investigated by Sun et al. (1995), the correction associated with the specific heat of moist air is expected to be less than $1 \%$. A second sink of energy that has been neglected in energy balance calculations is the expansion of air during evaporation under constant pressure (Paw U et al., 2000), which is implied if one accepts the corrections of Webb et al. (1980). The suggested method to correct for this effect is to use the sonic temperature in calculating sensible heat flux instead of the estimated 'dry' air temperature (a value that is derived from the sonic temperature or measured independently using temperature sensors) in energy balance computations, which is a correction of about $7-8 \%$ of LE. Over deciduous forests, agricultural sites and many coniferous forests in FLUXNET, LE is close to or in excess of one-half $R_{\mathrm{n}}$ during the growing season, suggesting that this correction could approach $5 \%$ of $R_{\mathrm{n}}-G-S$ during the daytime and may improve energy balance closure by a similar magnitude.

\subsection{Low and high pass filtering}

Independent of other considerations, the eddy covariance technique underestimates the total mean turbulent flux to some extent because of high frequency loss (low pass filters). Unintentional low pass filters result from practical issues such as instrumentation that necessarily measures with finite response times, and at finite sampling increments and within finite volumes (Moore and Fisch, 1986). Spatial separation of sonic anemometers and scalar concentration instrumentation (i.e. IRGA) acts as a low pass filter. Additional high frequency losses, associated with tube attenuation and time lags, are present in systems using closed path IRGAs (Leuning and Judd, 1996). The averaging period used to define mean fluxes can 
cut-off low frequency contributions (high pass filter) (Moore, 1986; Aubinet et al., 2000).

Theoretical (Moore, 1986) analytical (Massman, 2000) and empirical (Goulden et al., 1997) approaches have been proposed to account for low and high frequency loss of flux. However, no standard method for estimating frequency response corrections is used across all FLUXNET sites, and the different correction methods do not always agree (Aubinet et al., 2000). Individual sites typically correct their data for high frequency losses based on personal preferences before submitting to the FLUXNET archive. For closed path IRGAs, corrections are often based on the assumption that $H$ defines the expected frequency distribution of mass and energy-transporting eddies (Ribmann and Tetzlaff, 1995).

One hypothesis is that some portion of the energy imbalance may result from underestimates in water vapor (LE) flux, as suggested by Dugas et al. (1991). Sensible heat flux is estimated using sonic anemometry, but the water vapor sensor is separated from the sonic anemometer (i.e. sensor separation acts as a low pass filter). Additional LE loss may occur using closed path systems because of tube attenuation or water vapor interactions with tubes and chamber walls (Goulden et al., 1997; Leuning and Judd, 1996). At the FLUXNET sites, there were no obvious differences in the energy imbalance between open and closed path IRGAs, which may indicate that these problems are small or that the frequency response corrections were applied appropriately. However, it is possible that the slightly lower OLS slope at low Bowen ratios using closed path sensors indicates an underestimate of water vapor fluxes.

High frequency corrections are expected to be less at tall-forested sites because turbulent time scales increase (Anderson et al., 1984; Baldocchi and Meyers, 1988). Energy balance closure was not generally superior at sites with tall vegetation, which may imply that the loss of high frequency flux was not the major source of the energy imbalance. FLUXNET sites that have closed path sensors often show correction terms as large as 15-30\% (Goulden et al., 1997; Berger et al., 2001), but there was no obvious difference in the imbalance between sites with both types of sensors. It was not possible to evaluate the effect of averaging time on the energy imbalance across all sites, but Goulden et al. (1997) found that averaging time did not change energy balance closure at a FLUXNET site in a spruce forest.

\subsection{Advection}

At nearly all FLUXNET sites, it is assumed that advection of scalars (including $\mathrm{CO}_{2}$ ), can be neglected (Paw U et al., 2000). Vertical advection is neglected by rotating the coordinate system so that the mean vertical velocity is always zero (McMillen, 1988). However, non-zero values of mean vertical velocity and vertical advection are realistic and can be induced by horizontal heterogeneity or mesoscale and synoptic scale forcing (Lee, 1998; Sun et al., 1998). Two types of flows may make the assumption of negligible mean vertical advection problematic at FLUXNET sites. First, horizontal heterogeneity in surface fluxes, even at scales much larger than typically required in micrometeorological studies, can promote local circulations and vertical motions that seriously compromise the zero vertical velocity assumption (Vidale et al., 1997; Sun et al., 1998; Leclerc et al., 2000). Similarly, even slight elevation gradients over a range of spatial scales can induce nocturnal drainage flows and advection near the surface during periods of strong static stability (Mahrt and Larsen, 1990; Lee, 1998).

The poor energy balance closure during nocturnal periods at FLUXNET sites, especially when turbulence was weak (low friction velocity), is consistent with the establishment of drainage flows that advect heat and water vapor (and $\mathrm{CO}_{2}$ ) to low terrain. Aubinet et al. (2000) and Blanken et al. (1998) have also shown that the energy imbalance during nocturnal periods is usually greatest when friction velocity is small. Lee and $\mathrm{Hu}$ (2002) hypothesized that the lack of energy balance closure during nocturnal periods was often the result of mean vertical advection.

If terrain-induced flow is the primary source of the energy imbalance, it would be expected that sites on 'flat' terrain should have better energy balance closure, especially during nocturnal periods. Although previous research suggests that terrain can affect the extent of closure (Kustas et al., 1991; Stannard et al., 1994) these studies also find a lack of closure at sites across a range topographic variations. In this study, closure was not obviously superior at sites reported to be on 'flat' terrain across the FLUXNET sites. However, the evaluation of terrain is highly subjective 
and can depend on spatial scales. Even at sites with locally flat terrain, larger scale elevation gradients may promote terrain-induced circulations.

Although nocturnal flows likely augment the relative energy imbalance compared to the daytime, the daytime imbalance suggests that daytime advection or other processes are also potentially important. It is also reasonable to suspect that the lack of closure may result from small but multiple issues that reduce the magnitude of the estimated fluxes.

\subsection{Implications for $\mathrm{CO}_{2}$ flux}

A primary motivation for the FLUXNET network is to quantify carbon cycling over specific ecosystems around the globe. A general lack of energy balance closure in the network may be a concern that $\mathrm{CO}_{2}$ flux estimates may be in error; however, it is not a conclusive test. Errors in the energy balance calculations can be independent of $\mathrm{CO}_{2}$ flux estimates and vice versa, implying that the consequences of the imbalance on interpreting $\mathrm{CO}_{2}$ fluxes are largely dependent on the reasons for the imbalance at FLUXNET stations (Table 4).

Sampling errors associated with differences in source area among the energy balance terms would not have direct implications on the quality of $\mathrm{CO}_{2}$ flux measurements. An inaccurate account of $G, S$ and $Q$, which is probable at some sites in FLUXNET, was also not expected to have direct implications on $\mathrm{CO}_{2}$ measurements, but different $\mathrm{CO}_{2}$ sinks may be present, such as diffusion into groundwater (Jones and Mullholland, 1998). Instrument biases in energy measurements (net radiation, soil heat flux) would not have implications on the quality of $\mathrm{CO}_{2}$ measurements, but biases associated with sonic anemometers or IRGAs could also bias $\mathrm{CO}_{2}$ fluxes. If low or high pass filters are the primary source of the energy imbalance, then errors in the $\mathrm{CO}_{2}$ flux should be expected, especially because the $\mathrm{CO}_{2}$ measuring device (IRGA) and sonic anemometer are separated spatially. Similarly, if mean horizontal or vertical advection are affecting energy balance closure, advection of $\mathrm{CO}_{2}$ should also be suspected. However, because there are spatial and temporal differences in source strengths between heat, water and $\mathrm{CO}_{2}$, the magnitude of advection fluxes can be different for the different scalars. For example, although the transport mechanisms for heat, water and $\mathrm{CO}_{2}$ are similar, the $\mathrm{CO}_{2}$ flux is more susceptible to nocturnal drainage. The integrated $\mathrm{CO}_{2}$ flux is the difference in two large terms, carbon uptake associated with photosynthesis, and respiration. Systematic errors in nocturnal respiration can have large implications on long-term estimates of carbon sequestration (Moncrieff et al., 1996). Alternatively, the nocturnal water vapor flux is typically of relatively minor quantitative importance to the long-term water balance. This may be one reason why the catchment water budget (Barr et al., 1994; Wilson et al., 2001) is easier to close than the carbon budget, although the estimated carbon budget may also be nearly closed on an annual basis at some sites (Curtis et al., 2002).

Because the magnitude of the mean $\mathrm{CO}_{2}$ flux at a given PAR was approximately 15\% lower when the turbulent energy fluxes are low relative to available energy, there is some reason to suspect that the daytime energy imbalance is also affecting $\mathrm{CO}_{2}$ fluxes at FLUXNET sites. Mean warm season differences in the nocturnal $\mathrm{CO}_{2}$ fluxes of nearly $2.5 \mu \mathrm{mol} \mathrm{m}{ }^{-2} \mathrm{~s}^{-1}$ (50\%) between periods with acceptable and poor energy balance closure also suggests a link between the imbalance and $\mathrm{CO}_{2}$ flux estimates. Using chamber estimates as a reference, Twine et al. (2000) also found evidence that eddy covariance estimates of the $\mathrm{CO}_{2}$ flux were underestimated during periods of energy imbalances. It is still possible that the energy imbalance and the lower $\mathrm{CO}_{2}$ fluxes occur during calmer periods when both energy and carbon storage terms are large and underestimated, but these responses may also suggest advection, drainage flows or some other problem associated with the eddy covariance technique.

Previous studies have indicated that nocturnal respiration estimates are in better agreement with chamber measurements during periods of greater turbulent intensity (friction velocity) (Goulden et al., 1997; Law et al., 1999). This study and Blanken et al. (1998) suggests similar improvement in energy balance closure with friction velocity. These corresponding relationships with friction velocity may support the notion that data quality is improved during periods of higher turbulent mixing (Goulden et al., 1997). However, there is little evidence that nocturnal energy balance closure is acceptable above a 'threshold' friction velocity, even within particular sites, which may have implications on using this technique for accepting or rejecting nocturnal $\mathrm{CO}_{2}$ fluxes (Goulden et al., 1997; Jarvis et al., 
1997; Hollinger et al., 1999; Aubinet et al., 2000). The large intercepts and poor correlation of the OLS energy balance regressions during nocturnal periods at all values of friction velocity are also a concern.

\section{Conclusions}

1. There was a general lack of energy balance closure at FLUXNET sites, with the scalar fluxes of sensible and LE being underestimated and/or available energy being overestimated. The mean imbalance was in the order of $20 \%$.

2. Energy balance closure is typically poor during nocturnal periods, especially when the turbulent mixing is weak. On average, energy balance closure was better in the afternoon than in the morning, possibly suggesting the underestimation of storage terms, which are usually larger in the morning.

3. No conclusive differences were observed between sites using open and closed path IRGAs or on sites with 'flat' or sloping terrain.

4. The energy imbalance persisted during all seasons of the year and at all Bowen ratios, but the regression slope was typically closer to 1 during the warm season.

5. The mean relationship between $\mathrm{CO}_{2}$ and PAR, as well as nocturnal respiration, were affected by the extent of energy balance closure. This evidence suggests a link between $\mathrm{CO}_{2}$ fluxes and energy balance closure, it is still uncertain if the mechanisms creating the imbalance and the lower $\mathrm{CO}_{2}$ flux estimates are similar.

\section{Acknowledgements}

This work is the result of the FLUXNET (NASA) Workshop in Marconi, CA, USA (June 2000). It is also a contribution to the AmeriFlux program (US Department of Energy's Terrestrial Carbon Program). We thank Bruce Hicks, Marc Pitchford and Jose Fuentes for reviewing and improving this manuscript.

\section{References}

Anderson, D.E., Verma, S.B., Rosenberg, N.J., 1984. Eddy correlation measurements of $\mathrm{CO}_{2}$, latent heat and sensible heat fluxes over a crop surface. Bound.-Lay. Meteorol. 29, 263-272.
Anthoni, P., Law, B.E., Unsworth, M.J., 1999. Carbon and water vapor exchange of an open-canopied ponderosa pine ecosystem. Agric. For. Meteorol. 95, 151-168.

Anthoni, P., Law, B.E., Unsworth, M.J., Vong, R.J., 2000. Variation in net radiation over heterogeneous surfaces: measurements and simulations in a juniper-sagebrush ecosystem. Agric. For. Meteorol. 102, 275-286.

Aston, A.R., 1985. Heat storage in a young eucalypt forest. Agric. For. Meteorol. 35, 281-287.

Aubinet, M., Grelle, A., Ibrom, A., Rannik, Ü., Moncrieff, J., Foken, T., Kowalski, A.S., Martin, P.H., Berbigier, P., Bernhofer, Ch., Clement, R., Elbers, J., Granier, A., Grünwald, T., Morgenstern, K., Pilegaard, K., Rebmann, C., Snijders, W., Valentini, R., Vesala, T., 2000. Estimates of the annual net carbon and water exchange of European forests: the EUROFLUX methodology. Adv. Ecol. Res. 30, 114-175.

Baldocchi, D.D., Meyers, T.P., 1988. A spectral and lag-correlation analysis of turbulence in a deciduous forest canopy. Bound.-Lay. Meteorol. 45, 31-58.

Baldocchi, D.D., Meyers, T.P., 1998. On using eco-physiological, micrometeorological and biogeochemical theory to evaluate carbon dioxide, water vapor and trace gas fluxes over vegetation: a perspective. Agric. For. Meteorol. 90, 1-25.

Baldocchi, D.D., Law, B.E., Anthoni, P.M., 2000. On measuring and modeling energy fluxes above the floor of a homogeneous and heterogeneous conifer forest. Agric. For. Meteorol. 102, 187-206.

Baldocchi, D., Falge, E., Gu, L., Olson, R., Hollinger, D., Running, S., Anthoni, P., Bernhofer, C., Davis, K., Evans, R., Fuentes, J., Goldstein, A., Katul, G., Law, B., Lee, X., Malhi, Y., Meyers, T., Munger, W., Oechel, W., Paw U, K.T., Pilegaard, K., Schmid, H.P., Valentini, R., Verma, S., Vesala, T., Wilson, K., Wofsy, S., 2001. FLUXNET: a new tool to study the temporal and spatial variability of ecosystem-scale carbon dioxide, water vapor and energy flux densities. Bull. Am. Meteorol. Soc. 82, 2415-2434.

Barr, A.G., King, K.M., Gillespie, T.J., den Hartog, G., Neumann, H.H., 1994. A comparison of Bowen ratio and eddy-correlation sensible and latent-heat flux measurements above deciduous forest. Bound.-Lay. Meteorol. 7, 21-41.

Berger, B.W., Davis, K.J., Yi, C., Bakwin, P.S., Zhao, C., 2001. Long-term carbon dioxide fluxes from a very tall tower in a northern forest. J. Atmos. Ocean. Technol. 18, 529-542.

Blanken, P.D., Black, T.A., Neumann, H.H., Den Hartog, G., Yang, P.C., Nesic, Z., Staebler, R., Chen, W., Novak, M.D., 1998. Turbulent flux measurements above and below the overstory of a boreal aspen forest. Bound.-Lay. Meteorol. 89, 109-140.

Buchan, G.D., 1989. Soil heat flux and soil surface energy balance: a clarification of concepts. In: Proceedings of the Fourth Australasian Conference on Heat and Mass Transfer. University of Caterbury, Christchurch, New Zealand.

Businger, J.A., 1986. Evaluation of the accuracy with which dry deposition can be measured with current micrometeorological techniques. J. Clim. Appl. Meteorol. 25, 1100-11224.

Collatz, G.J., Ball, J.T., Grivet, C., Berry, J.A., 1991. Regulation of stomatal conductance and transpiration: a physiological model of canopy processes. Agric. For. Meteorol. 54, 107-136. 
Culf, A.D., Allen, S.J., Gash, J.H.C., Lloyd, C.R., Wallace, J.S., 1993. The energy and water budgets of an area of patterned woodland in the Sahel. Agric. For. Meteorol. 66, 65-80.

Culf, A.D., Folken, T., Gash, J.H.C., 2002. The energy balance closure problem. In: Vegetation, Water, Humans and the Climate., (in press).

Curtis, P.S., Hanson, P.J., Bolstad, P., Barford, C., Randolph, J.C., Schmid, H.P., Wilson, K.B., 2002. Biometric and eddy covariance based estimates of ecosystem carbon storage in five eastern North American deciduous forests. Agric. For. Meteorol. 113, 3-19.

Dugas, W.A., Fritschen, L.J., Gay, L.W., Held, A.A., Matthias, A.D., Reicosky, D.C., Steduto, P., Steiner, J.L., 1991. Bowen ratio, eddy correlation, and portable chamber measurements of sensible and latent heat flux over irrigated spring wheat. Agric. For. Meteorol. 56, 1-20.

Falge, E., Baldocchi, D., Olson, R.J., Anthoni, P., Aubinet, M., Bernhofer, C., Burba, G., Ceulemans, R., Clement, R., Dolman, H., Granier, A., Gross, P., Grünwald, T., Hollinger, D., Jensen, N.-O., Katul, G., Keronen, P., Kowalski, A., Ta Lai, C., Law, B.E., Meyers, T., Moncrieff, J., Moors, E., Munger, J.W., Pilegaard, K., Rannik, Ü., Rebmann, C., Suyker, A., Tenhunen, J., Tu, K., Verma, S., Vesala, T., Wilson, K., Wofsy, S., 2001. Gap filling strategies for long term energy flux data sets. Agric. For. Meteorol. 107, 71-77.

Field, R.T., Fritschen, L.J., Kanemasu, E.T., Smith, E.A., Stewart, J.B., Verma, S.B., Kustas, W.P., 1992. Calibration, comparison, and correction of net radiation instruments used during FIFE. J. Geophys. Res. 97 (D17), 18681-18695.

Folken, Th., Wichura, B., 1996. Tools for quality assessment of surface-based flux measurements. Agric. For. Meteorol. 78, 83105.

Goldstein, A.H., Hultman, N.E., Fracheboud, J.M., Bauer, M.R., Panek, J.A., Xu, M., Qi, Y., Guenther, A.B., Baugh, W., 2000. Effects of climate variability on the carbon dioxide, water, and sensible heat fluxes above a ponderosa pine plantation in the Sierra Nevada (CA). Agricultural and Forest Meteorology 101, 113-129.

Goulden, M.L., Daube, B.C., Fan, S.M., Sutton, D.J., Bazzaz, A., Munger, J.W., Wofsy, S.C., 1997. Physiological responses of a black spruce forest to weather. J. Geophys. Res. 102 (D24), 28987-28996.

Gu, J., Smith, E.A., Merritt, J.D., 1999. Testing energy balance closure with GOES-retrieved net radiation and in situ measured eddy correlation fluxes in BOREAS. J. Geophys. Res. 104 (D22), 27881-27893.

Halldin, S., Lindroth, A., 1992. Errors in net radiometry: comparison and evaluation of six radiometer designs. J. Atmos. Ocean. Technol. 9, 762-783.

Halldin, S., 2002. Radiation measurements in integrated terrestrial experiments. In: Vegetation, Water, Humans and the Climate. Springer, Berlin., (in press).

Hodges, G.B., Smith, E.A., 1997. Intercalibration, objective analysis, incomparison and synthesis of BOREAS surface net radiation measurements. J. Geophys. Res. 102 (D24), 288528900.

Hollinger, D.Y., Goltz, S.M., Davidson, E.A., Lee, J.T., Tu, K., Valentine, H.T., 1999. Seasonal patterns and environmental control of carbon dioxide and water vapour exchange in an ecotonal boreal forest. Glob. Change Biol. 5, 891-902.

Jarvis, P.G., Massheder, J.M., Hale, S.E., Moncrieff, J.B., Rayment, M., Scott, S.L., 1997. Seasonal variation of carbon dioxide, water vapor, and energy exchanges of a boreal spruce forest. J. Geophys. Res. 102, 28799-28985.

Jones, J.B., Mullholland, P.J., 1998. Carbon dioxide variation in a hardwood forest stream: an integrative measure of whole catchment soil respiration. Ecosystems 1, 183-196.

Kustas, W.P., Prueger, J.H., Hipps, L.E., Hatfield, J.L., Meek, D., 1998. Inconsistencies in net radiation estimates from use of several models of instruments in a desert environment. Agric. For. Meteorol. 90, 257-263.

Kustas, W.P., Prueger, J.H., Hatfield, J.L., Ramalingam, K., Hipps, L.E., 2000. Variability in soil heat flux from a mesquite dune site. Agric. For. Meteorol. 103, 249-264.

Kustas, W.P., Goodrich, D.C., Moran, M.S., et al., 1991. An interdisciplinary field-study of the energy and water fluxes in the atmosphere-biosphere system over semiarid rangelands-description and some preliminary-results. Bulletin of the American Meteorological Society 72, 1683-1705.

Lamaud, E., Ogee, J., Brunet, Y., Berbigier, P., 2001. Validation of eddy flux measurements above the understorey of a pine forest. Agric. For. Meteorol. 106, 187-203.

Law, B.E., Ryan, M.G., Anthoni, P.M., 1999. Seasonal and annual respiration of a ponderosa pine ecosystem. Glob. Change Biol. $5,169-182$.

Lee, X., 1998. On micrometeorological observations of surface-air exchange over tall vegetation. Agricultural and Forest Meteorology 91, 39-50.

Lee, X., Hu, X., 2002. Forest-air fluxes of carbon, water and energy over non-flat terrain. Bound.-Lay. Meteorol. 103, 277-301.

Leuning, R., Judd, M.J., 1996. The relative merits of open and closed path analysers for measurement of eddy fluxes. Global Change Biology 2, 241-253.

Liu, Y., Weaver, C.P., Avissar, R., 1999. Toward a parameterization of mesoscale fluxes and moist convection induced by landscape heterogeneity. J. Geophys. Res. 104 (D16), 19515-19533.

Mahrt, L., 1998. Flux sampling errors for aircraft and towers. J. Atmos. Ocean. Technol. 15, 416-429.

Mahrt, L., Larsen, S., 1990. Relation of slope winds to the ambient flow over gentle terrain. Bound.-Lay. Meteorol. 53, 93-102.

Massman, W.J., 2000. A simple method for estimating frequency response corrections for eddy covariance systems. Agric. For. Meteorol. 104, 185-198.

Mayocchi, C.L., Bristow, K.L., 1995. Soil surface heat flux: some general questions and comments on measurements. Agric. For. Meteorol. 75, 43-50.

McCaughey, J.H., 1985. Energy balance storage terms in a mature mixed forest at Petawawa, Ontario-a case study. Bound.-Lay. Meteorol. 31, 89-101.

McMillen, R.T., 1988. An eddy correlation technique with extended applicability to non-simple terrain. Bound.-Lay. Meteorol. 43, 231-245.

Meek, D.W., Prueger, J.H., 1998. Solutions for three regression problems commonly found in meteorological data analysis. In: Proceedings of the 23rd Conference on Agricultural Forest 
Meteorology. American Meteorological Society, Albuquerque, NM, November 2-6, 1998, pp. 141-145.

Moncrieff, J.B., Mahli, Y., Leuning, R., 1996. The propagation of errors in long-term measurements of land-atmosphere fluxes of carbon and water. Glob. Change Biol. 2, 231-240.

Moore, C.J., 1986. Frequency response corrections for eddy correlation systems. Bound.-Lay. Meteorol. 37, 17-35.

Moore, C.J., Fisch, G., 1986. Estimating heat storage in Amazonian tropical forest. Agric. For. Meteorol. 38, 147-169.

Oke, T.R., 1987. Boundary Layer Climates, 2nd Edition. Methuen, London.

Paw U, K.T., Baldocchi, D.D., Meyers, T.P., Wilson, K.B., 2000. Corrections of eddy covariance measurements incorporating both advective effects and density fluxes. Bound.-Lay. Meteorol. 97, 487-511.

Ribmann, J., Tetzlaff, G., 1995. Application of a spectral correction method for measurements of covariances with fast-response sensors in the atmospheric boundary layer up to a height of $130 \mathrm{~m}$ and testing the corrections. Bound.-Lay. Meteorol. 70, 293-305.

Schmid, H.P., 1997. Experimental design for flux measurements: matching scales of observations and fluxes. Agric. For. Meteorol. 87, 179-200.

Schmid, H.P., Cleugh, H.A., Grimmond, C.S.B., Oke, T.R., 1991. Spatial variability of energy fluxes in suburban terrain. Bound.-Lay. Meteorol. 54, 249-276.

Schmid, H.P., Grimmond, C.S.B., Cropley, F., Offerle, B., Su, H.-B., 2000. Measurements of $\mathrm{CO}_{2}$ and energy fluxes over a mixed hardwood forest in the mid-western United States. Agric. For. Meteorol. 103, 357-374.

Stannard, D.I., Blanford, J.H., Kustas, W.P., Nichols, W.D., Amer, S.A., Schmugge, T.J., Weltz, M.A., 1994. Interpretation of surface flux measurements in heterogeneous terrain during the Monsoon'90 experiment. Water Resour. Res. 30 (5), 1227-1239.

Sun, J., Esbensen, S.K., Mahrt, L., 1995. Estimation of surface heat flux. J. Atmos. Sci. 52, 3162-3171.

Sun, J., Desjardins, R., Mahrt, L., Macpherson, I., 1998. Transport of carbon dioxide, water vapor, and ozone by turbulence and local circulations. J. Geophys. Res. 103, 25873.
Twine, T.E., Kustas, W.P., Norman, J.M., Cook, D.R., Houser, P.R., Meyers, T.P., Prueger, J.H., Starks, P.J., Wesely, M.L., 2000. Correcting eddy-covariance flux underestimates over a grassland. Agric. For. Meteorol. 103, 279-300.

VanLoon, W.K.P., Bastings, H.M.H., Moors, E.J., 1998. Calibration of soil heat flux sensors. Agric. For. Meteorol. 92, 1-8.

Verhoef, A., van den Hurk, B.J.J.M., Jacobs, A.F.G., Heusinkveld, B., 1996. Thermal properties for vineyard (EFEDA-I) and savanna (HAPEX-Sahel) sites. Agric. For. Meteorol. 78, $1-18$.

Verma, A.B., Baldocchi, D.D., Anderson, D.E., Matt, D.R., Clement, R.J., 1986. Eddy fluxes of $\mathrm{CO}_{2}$, water vapor, and sensible heat over a deciduous forest. Bound.-Lay. Meteorol. 36, 71-91.

Vidale, P.L., Pielke, R.A., Steyaert, L.T., Barr, A., 1997. Case study modeling turbulent and mesoscale fluxes over the BOREAS region. J. Geophys. Res. D24, 29167-29188.

Villalobos, F.J., Fereres, 1990. Evaporation measurements beneath corn, cotton, and sunflower canopies. Agron. J. 82, 11531159 .

Webb, E.K., Pearman, G.I., Leuning, R., 1980. Correction of flux measurements for density effects due to heat and water vapor transfer. Quart. J. R. Meteorol. Soc. 106, 67-90.

Wilson, K.B., Baldocchi, D.D., 2000. Seasonal and interannual variability of energy fluxes over a broadleaved temperate deciduous forest in North America. Agric. For. Meteorol. 100, $1-18$.

Wilson, K.B., Hanson, P.J., Baldocchi, D.D., 2000. Factors controlling evaporation and energy balance partitioning beneath a deciduous forest over an annual cycle. Agric. For. Meteorol. $102,83-103$.

Wilson, K.B., Hanson, P.J., Mullholland, P.J., Baldocchi, D.D., Wullschleger, S.D., 2001. A comparison of methods for determining forest evapotranspiration and its components: sap flow, soil water budget, eddy covariance and catchment water balance. Agric. For. Meteorol. 106, 153-168.

Wyngaard, J.C., 1981. The effects of probe-induced flow distortion on atmospheric turbulence measurements. J. Appl. Meteorol. 20, 784-794. 